\title{
Have commodities become a financial asset? Evidence from ten years of Financialization is
}

\author{
Zeno Adams*, Solène Collot, Maria Kartsakli \\ Swiss Institute of Banking and Finance (s/bf), University of St. Gallen, Unterer Graben 21, 9000 St. Gallen, Switzerland
}

\section{A R T I C L E I N F O}

\section{Article history:}

Received 15 July 2019

Received in revised form 5 April 2020

Accepted 15 April 2020

Available online 25 May 2020

\section{JEL classification:}

Q40

Q41

G14

Keywords:

Crude oil

Commodities

Financialization

R-squared decomposition

\begin{abstract}
A B S T R A C T
The financialization of commodity markets over the last decade has changed the behavior of commodity prices in fundamental ways. In this paper, we uncover the gradual transformation of commodities from a physical to a financial asset. Although economic demand and supply factors continue to play an important role, recent indicators associated with financialization have emerged since 2008. We show that financial variables have become the main driving factors explaining the variation in commodity returns and volatility today. Our findings have important implications for portfolio analysis and for the effectiveness of hedging in commodity markets.
\end{abstract}

c) 2020 Elsevier B.V. All rights reserved.

\section{Introduction}

Commodities are considered real assets. Prices are determined by the demand for production inputs and the extraction and mining capacity of commodity suppliers. A long position in a commodity futures contract is a bet on rising prices that is disconnected from the physical world. The large majority of commodity futures are closed prior to maturity so that trading in futures does not affect the price of physical commodities. This is the traditional view of segmented commodity futures and spot markets.

This view has been challenged by recent events that are caused by the increased presence of financial investors in commodity markets. The phenomenon is known as the "financialization of commodity markets" and is estimated to have emerged around 2004 when inflows into commodity markets increased from $\$ 15$ billion to over $\$ 450$ billion in April 2011 (Bicchetti and Maystre, 2012). There has been considerable effort in the recent academic literature to identify and measure the impact of financial investors and to investigate the implications for market participants. Broadly defined, the literature has identified three areas that underwent significant changes since 2004. These are illustrated in Panel A of Fig. 1.

\footnotetext{
is We would like to thank Christoph Aymanns, Robert Bianchi, Ulrike Grömping, Elli Kartsakli, Andrei Kirilenko, Marcel Prokopczuk, Thomas Walther, and Cynthia Wu for valuable comments and suggestions. We also thank Richard Papp for valuable research assistance. This work is supported by GFF fund no. 2130882 and SNF no. 100018_178903.

* Corresponding author.

E-mail addresses: zeno.adams@unisg.ch (Z. Adams), solene.collot@unisg.ch (S. Collot), maria.kartsakli@unisg.ch (M. Kartsakli).
}

The majority of current empirical studies focuses on detecting a link between inflows from financial investors on the one hand, and (1) futures prices, (2) spot prices, and (3) the comovement with financial assets on the other.

Financial investors typically have net long positions in broad commodity indices such as the S\&P GSCI Composite Index or the Bloomberg Commodity Index (Irwin and Sanders, 2011). Futures prices for a wide range of commodities started to increase following large-scale inflows from financial investors (Cheng and Xiong, 2014). These inflows were documented in a first generation of empirical work that investigated whether these types of investors were responsible for generating a price bubble (Kaufmann and Ullman, 2009; Kaufmann, 2011; Vansteenkiste, 2011). To conserve space, we do not present a full overview of the large and growing literature in this introduction. A summary of the main papers on financialization with an emphasis on those published in Energy Economics can be found in Appendix B.

The second change occurred in the returns and the volatility of commodity spot prices. In particular, financialization and large-scale speculation in commodity futures markets appears to have significant spillover effects on the prices of physical commodities. The link between speculation and physical prices is a controversial issue. In a recent literature review, Haase et al. (2016) examine 100 papers that have been published on the topic of financialization in commodity markets over the last decade. The authors conclude that the number of papers finding a positive effect of speculation and the ones finding a negative effect are about the same. The overall picture is therefore rather mixed. 
The most visible change is perhaps the dramatic increase in comovement, both within the commodity universe (Tang and Xiong, 2012), and with the general stock market (Cheng and Xiong, 2014). The rise in correlation has been documented at full length in the empirical literature. However, the role of financial investors in generating this comovement is still being discussed with some authors pointing towards a crisis rather than a financialization effect (Brunnermeier and Pedersen, 2009).

Given the size of the current literature on financialization in commodity markets, the lack of consensus concerning its core issues seems surprising. However, researchers are confronted with a number of empirical challenges that, if not properly addressed, can produce contradictory findings. This is illustrated in Panel B of Fig. 1. One of the problems faced by researcher is that the variables of interest are not determined by financial investors alone, but by joint decisions made by both, financial investors and commercial hedgers. Cheng and Xiong (2014) highlight the role of informational frictions in determining the interaction between both groups of market players. However, classification of traders into one of these groups based on CFTC data has been criticized, as many large traders engage in activities that are associated with both groups (Irwin and Sanders, 2011). Another issue that was particularly present in early empirical studies is endogeneity between financial investor activity and the impact on futures prices: while buying pressure from financial investors can cause rising prices, a positive price trend can also attract more investors. Finally, the financialization of commodity markets also has important social implications which

\section{A: Research Focus of Current Literature}

\section{Financial Investors}

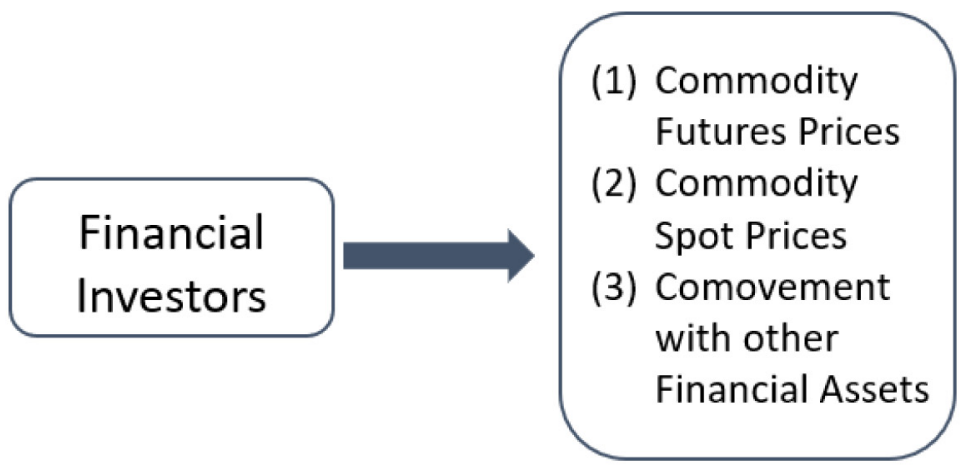

\section{B: Empirical Challenges and Research Incentives}
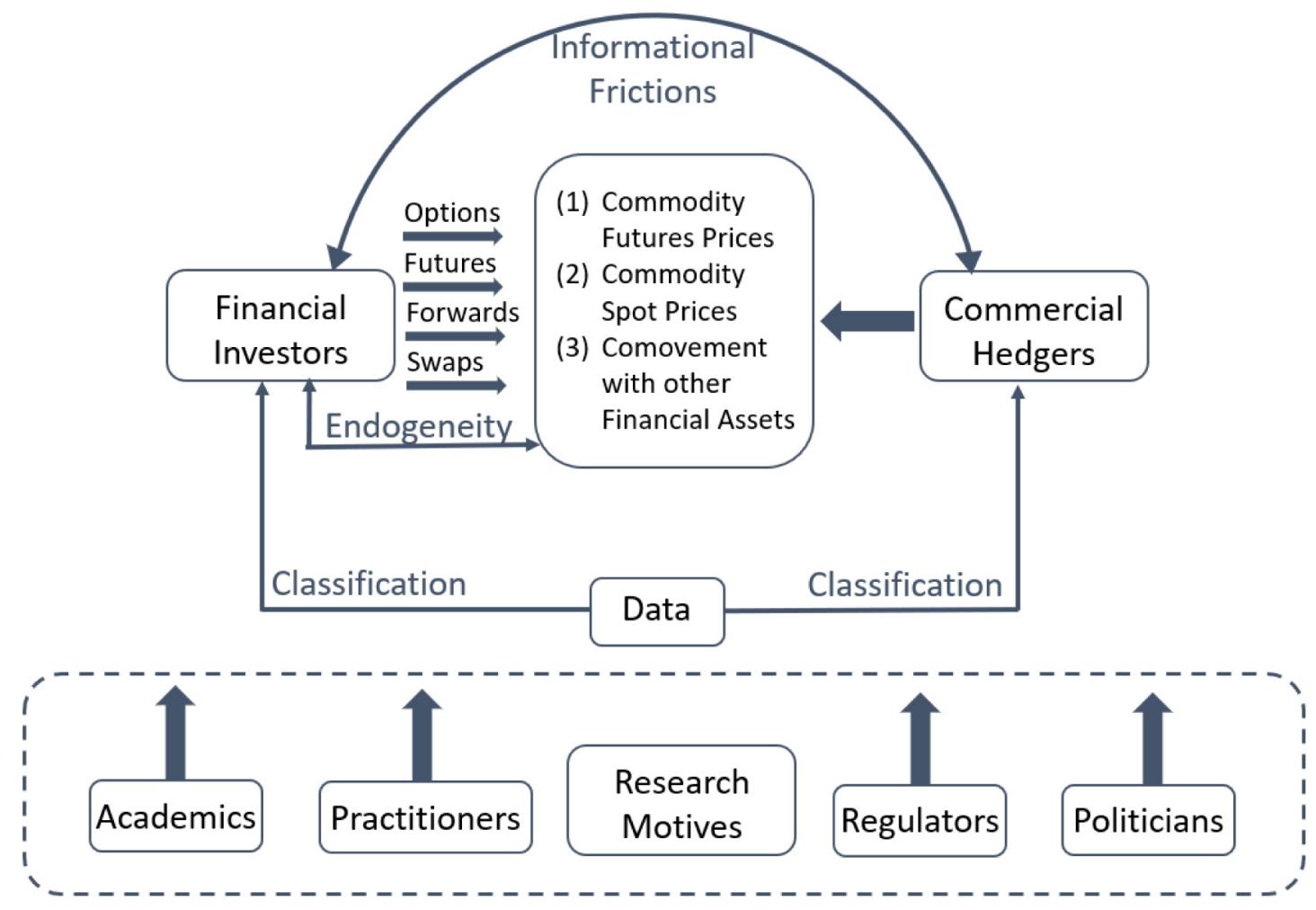

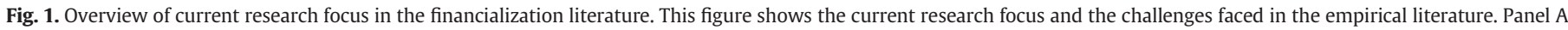

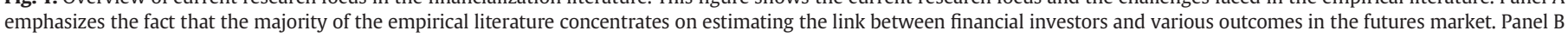
shows the complexity of the topic and the resulting challenges in empirical research. 
generated an interest in this topic beyond the academic community. As a result, not only academic scholars, but also practitioners, regulators, and even politicians have contributed to the debate, each arguing with different research motives and incentives. ${ }^{1}$ In summary, the topic is complex and multifaceted.

An important assumption underlying current empirical studies is a continuous presence of financial investors that motivates and justifies an examination of this topic. Cheng et al. (2015) show how financial investors can dominate trading activity during normal market times, but may retreat quickly from commodity markets during times of financial distress. If the presence of financial investors is changing over time, the impact and importance of studying financialization is also changing over time. We aim to contribute to this issue with an empirical examination of the presence of financial investors in commodity markets. In this paper, we propose a simple but effective measure to quantify the presence of financial investors. We show that investor presence has an important element of time variation. While financial investors seem to have been particularly active from 2008 to 2014, we find evidence of a weakening of this relationship, pointing towards a possible definancialization since June 2014. Our study is related to Zhang et al. (2017), who were one of the first to find evidence of a possible definancialization. They show that the comovement between oil price volatility and the VIX can be explained by both, fundamental economic variables and investor sentiment. Zhang et al. (2017) argue that the current de-financialization is a temporary phenomenon that was caused by the shale oil boom and subsequent oil price drop in 2014. A definite conclusion on this issue would be premature at this time but our empirical findings can be interpreted in a similar way.

In examining this issue, we use fundamental economic variables that have been the traditional drivers of commodities, as well as more recent variables that have been associated with financialization. Our empirical strategy is based on a simple idea: if financial variables have recently become more relevant than economic variables, we should expect financial variables to be better at explaining the variation of commodity prices over time than fundamental economic factors. Following this idea, we evaluate the contribution of each factor to the R-squared of a rolling window regression. Focusing on the R-squared and its decomposition, rather than the regression coefficients, has a number of advantages. First, the coefficient estimates are generally not useful for answering the question whether a variable is important for explaining commodity price changes. For instance, a key variable in our empirical setup is a measure of macroeconomic uncertainty. In a regression of oil volatility on macroeconomic uncertainty and other control variables, we find that the uncertainty coefficient is estimated to be 45 in the pre-financialization period and 23 in the following financialization period. Both estimates are statistically significant. From these coefficient estimates, one could conclude that macroeconomic uncertainty has become less important for explaining the variation in crude oil volatility. The R-squared decomposition that we apply in our analysis however shows that macroeconomic uncertainty is not less, but more important during the financialization period. During financialization, macroeconomic uncertainty explains a much larger proportion of the time variation in commodity volatility than in previous years. Our methodological approach therefore has a number of advantages over standard regression tables.

A side effect of our approach is that it allows for the presence of endogeneity. For instance, the risk premium that reflects the trading demand of financial investors not only affects commodity prices, but rising prices also attract investors into the market which in turn affects the risk premium. While the presence of endogeneity prevents us from estimating the causal effect, we can measure the contribution of the interaction between risk premium and prices on the R-squared of the regression model. Since we rely on variables for which other studies have already confirmed a causal link to commodity price dynamics, we build our

\footnotetext{
${ }^{1}$ See for instance the statements by then British Prime Minister Gordon Brown and French President Nicolas Sarkozy in 2009 (Brown and Sarkozy, 2009)
}

analysis on the R-squared decomposition without the need to verify causality. ${ }^{2}$ The result is an intuitive and direct interpretation of the importance of traditional economic variables on the one hand, and financialization indicators on the other. The outcome variables of interest are prices, returns, and the volatility of crude oil and other frequently traded commodities. Our main finding is that economic fundamental variables continue to play an important role but that the influence of financial variables has dramatically increased over time. During the financialization period, we find that from a $\$ 1$ change in crude oil prices, $35 \mathrm{cts}$. can be explained by changes in financial variables and only $22 \mathrm{cts}$. by economic fundamentals. These effects are even larger for volatility where we find that financial variables explain the majority of the variation in crude oil volatility (56\%), whereas economic fundamental variables can only explain $21 \%$. We conclude that financialization partly transformed commodities from a physical to a financial asset in terms of pricing behavior. We also find indications that the financialization effect is currently weaker and that commodities may have entered a period of de-financialization. The role of financial investors for commodity markets is therefore likely to have declined in recent years. Our empirical findings are in line with Aromi and Clements (2019) who investigate the role of the oil related information flows. They show that the rate of information flow has a negative impact on the correlation between oil prices and stock prices. In this context, the oil price drop of 2014 generated a surge in information flow that insulated oil markets from shocks in financial markets. De-financialization can be interpreted in this light as a consequence of an increase in oil related information relative to stock market related news.

Our empirical results have important implications for the diversification benefits of commodity investors and the hedging effectiveness of commodity producers. For instance, Badshah et al. (2019) show that risk managers base the timing and size of their hedging programs on future price expectations. Since informational frictions between financial investors and commercial hedgers become larger during times of uncertainty, commercial hedgers need to adjust optimal hedge ratios in commodities in order to mitigate stock market risks.

The remainder of the paper is organized as follows. Section 2 describes the methodology for measuring variable importance by decomposing the regression R-squared. We argue that our simple approach can address many of the shortcomings impairing other empirical findings in the literature. In Section 3, we discuss the economic and financial key variables for our paper. While the economic variables are well known, we thoroughly discuss the new financial variables that have emerged as important indicators of financialization over the last years. Section 4 shows the empirical results and discusses the implications for crude oil as a commodity. We present clear evidence for the disruptive effects of financialization, but also find that the dominating effect of financial variables has been declining recently. We discuss the implications of this recent de-financialization period and provide a tentative outlook for its future role. In Section 5, we extend our analysis to other commodities and examine the robustness of our results with respect to the specific functional form of our regression model. Section 6 concludes.

\section{A decomposition of commodity prices}

Monthly changes in commodity prices can be explained by economic fundamental variables on the one hand, and a set of financialization indicators on the other. While financialization is a recent phenomenon that is not yet fully understood, we show that its impact on commodity price movements is very real. In this chapter, we decompose the total variation of commodity prices into these two main categories. This decomposition can provide useful information about the relative importance and will be

\footnotetext{
2 Two papers that stand out for their strong empirical identification are Cheng et al. (2015) who circumvent the endogeneity problem by focusing on risk rather than prices, and Henderson et al. (2015) who use data on exogenous investment flows of commodity-linked notes.
} 
Table 1

Calculation example for sequentially added variances.

\begin{tabular}{ccc}
\hline Permutation & $\operatorname{var}\left(Y \mid X_{j}, j \in S\right)$ & $\operatorname{var}\left(Y \mid X_{M}, M \in M \cup S\right)$ \\
\hline $\mathbf{1}$ & $\operatorname{var}(Y)$ & $\operatorname{var}\left(Y \mid X_{1}, X_{2}, X_{3}\right)$ \\
$\mathbf{3}$ & $\operatorname{var}(Y)$ & $\operatorname{var}\left(Y \mid X_{1}, X_{3}, X_{2}\right)$ \\
$\mathbf{4}$ & $\operatorname{var}\left(Y \mid X_{2}, X_{3}\right)$ & $\operatorname{var}\left(Y \mid X_{1}, X_{2}, X_{3}\right)$ \\
$\mathbf{5}$ & $\operatorname{var}\left(Y \mid X_{3}, X_{2}, X_{2}\right)$ \\
$\mathbf{6}$ & $\operatorname{var}\left(Y \mid X_{2}, X_{3}\right)$ & $\operatorname{var}\left(Y \mid X_{1}, X_{2}, X_{3}\right)$ \\
& $\operatorname{var}\left(Y \mid X_{3}, X_{2}\right)$ & $\operatorname{var}\left(Y \mid X_{1}, X_{3}, X_{2}\right)$ \\
\hline
\end{tabular}

This table shows the $p !=6$ permutations for a simple linear regression model with $p=3$ regressors. Note that permutation 1 and 2 lead to the same value. The same holds for permutations 5 and 6 . There are therefore only 4 unique values. The measure $L M G(x 1)$ denotes the contribution of the variable $x 1$ to the explanatory power of the model and is computed as the average of the difference between column 2 and 3 divided by the total variance $\operatorname{Var}(Y)$ (see Eq. (3)).

the main source of evidence for the emerging dominance of financialization in explaining commodity price movements. The measurement and quantification of variable importance is a long-standing question in statistics. A recent overview article is provided by Grömping (2015). Perhaps the most intuitive approach is to observe the increase in R-squared when a variable is added to a linear regression model. Unfortunately, the R-squared value of a regression is conditional on all other variables so that adding or removing a regressor alters the result. ${ }^{3}$

In this paper, we adopt a method originally proposed by Lindeman et al. (1980) and further developed by Kruskal (1987). This approach has been termed the LMG method, named after its authors. Grömping (2015) shows that the LMG approach is superior to a number of other methods proposed in this field which either do not decompose the overall R-squared, estimate negative R-squared contributions, or fail to be scale invariant. Most importantly, LMG is not order dependent since the average over all possible regressor orderings is taken. ${ }^{4}$ At the center of this approach lies the variance of $Y$ conditional on some regressor $X_{j}, j \in S$. The dependent variable $Y$ measures the prices, returns or volatilities of a commodity and the set of control variables $S$ contains the regressors excluding the variable whose importance we aim to determine. When the variable of interest $X_{m}$ is added to the model, the set of explanatory variables encompasses $M U S$ and the conditional variance of $Y$ is reduced. The sequentially added variance svar measures the contribution of the variable $X_{m}$ to the overall explanatory power of the model:

$\operatorname{svar}(M \mid S)=\operatorname{var}\left(Y \mid X_{j}, j \in S\right)-\operatorname{var}\left(Y \mid X_{m}, m \in M \cup S\right)$

Since adding a variable will reduce the conditional variance of $Y$, svar will be non-negative. ${ }^{5}$ As an example, consider a linear regression model with three regressors:

\footnotetext{
3 The situation simplifies considerably when the regressors are uncorrelated in which case the R-squared is independent from the presence of other variables. However, this special case is of little practical relevance.

${ }^{4}$ A theoretical justification is provided by Huettner and Sunder (2012) who show that the LMG method has a counterpart in cooperative game theory where the "worth" (Rsquared) is efficiently distributed to the "players" (regressors) in a way that certain desirable properties are satisfied.

${ }^{5}$ Note that the conditional variance of $Y$ can be described as $\operatorname{var}(Y \mid X)=E\left(Y^{2} \mid X\right)-[E(Y \mid$ $X)]^{2}$ (Casella and Berger, 2002). The first term on the right hand side of this expression is the fitted values from a regression of $Y^{2}$ on the set of regressors in $X$. The second term is the squared fitted values from a regression of $Y$ on the same regressors. The conditional variance is therefore easy to estimate in an OLS framework.
}

$y=\alpha+\beta_{1} x_{1}+\beta_{2} x_{2}+\beta_{3} x_{3}+\varepsilon$.

We are interested in the contribution of $x_{1}$ to the explanatory power of the model. There are $p !=3 !=6$ permutations for which we can arrange the regressors in Eq. (2) and, hence, six different ways to measure the contribution of $x_{1}$. To illustrate this case the six permutations are listed in Table 1. The second column shows the variance of $Y$ conditional on the regressors in $S$ and therefore excluding the variable of interest, $x_{1}$.

The third column shows the conditional variance of $Y$ when $x_{1}$ is added to the model. The variables which do not enter the regression are indicated in grey. The sequentially added variance in Eq. (1) is then the difference between the second and the third column. The contribution of the variable $x_{1}$ to the explanatory power of the model is denoted as $\operatorname{LMG}\left(x_{1}\right)$ and is the fraction of the total variance of $Y$ explained by the average over all permutations:

$\operatorname{LMG}\left(x_{1}\right)=\frac{\frac{1}{p !} \sum_{i=1}^{p !} \operatorname{svar}\left(x_{1} \mid S(\pi)\right)}{\operatorname{Var}(Y)}$

The set of regressors $S$ changes over permutation $\pi$ as illustrated in Table 1. Note that the first and the second permutations in Table 1 yield identical results. The same holds true for permutations five and six since the reordering of included variables does not change the conditional variance. Accordingly, there are only 4 unique values for svar in Table 1. Although this decision has little impact on the result, we follow the literature and sum over all six permutations. ${ }^{6}$ In our example, there are three $\mathrm{LMG}$ values $\left\{L M G\left(x_{1}\right), L M G\left(x_{2}\right), L M G\left(x_{3}\right)\right\}$ which together sum up to the overall R-squared of the regression model in Eq. (2). For the analysis in this paper we use the LMG approach to decompose the variation in commodity prices into economic fundamentals and financialization variables. This decomposition provides important evidence for the recent rise in financialization driven price movements.

\footnotetext{
${ }^{6}$ Our results are very close to those obtained with the R package relaimpo (Grömping, 2006) which also sums over all $p$ ! permutations.
} 


\section{A: Crude Oil Spot Index and S\&P 500}

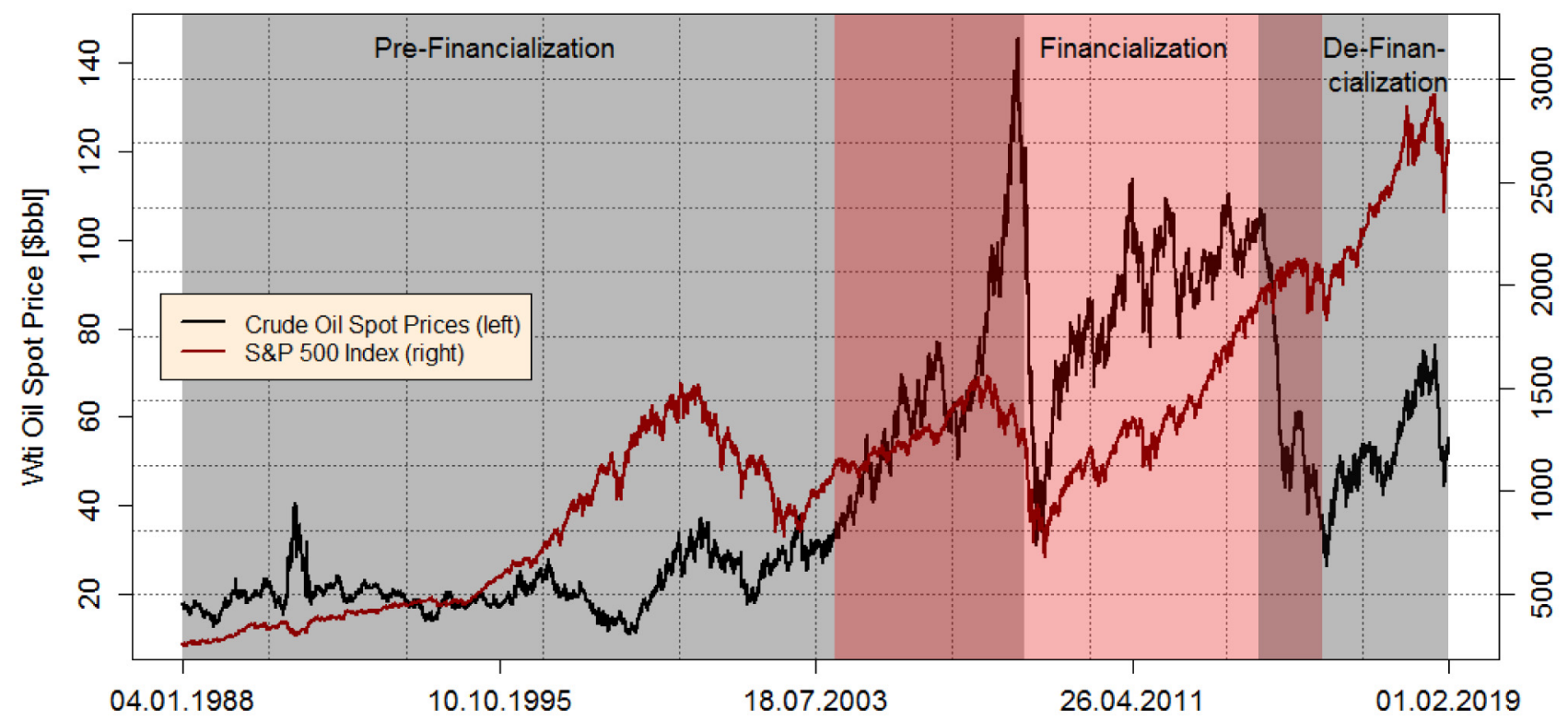

B: Public and Private Derivative Market Activity

Exchange Traded Contracts (Crude Oil)

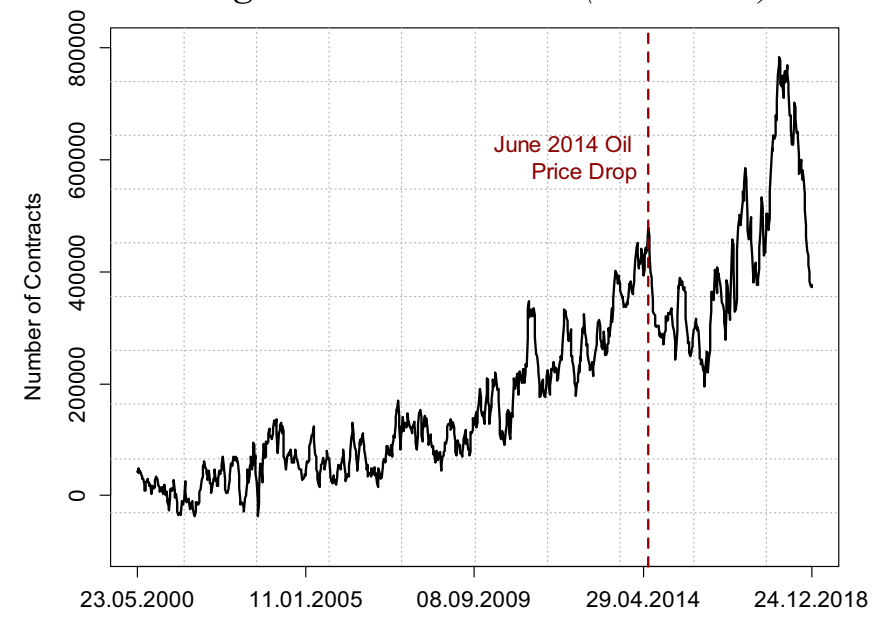

OTC Contracts (All Commodities)

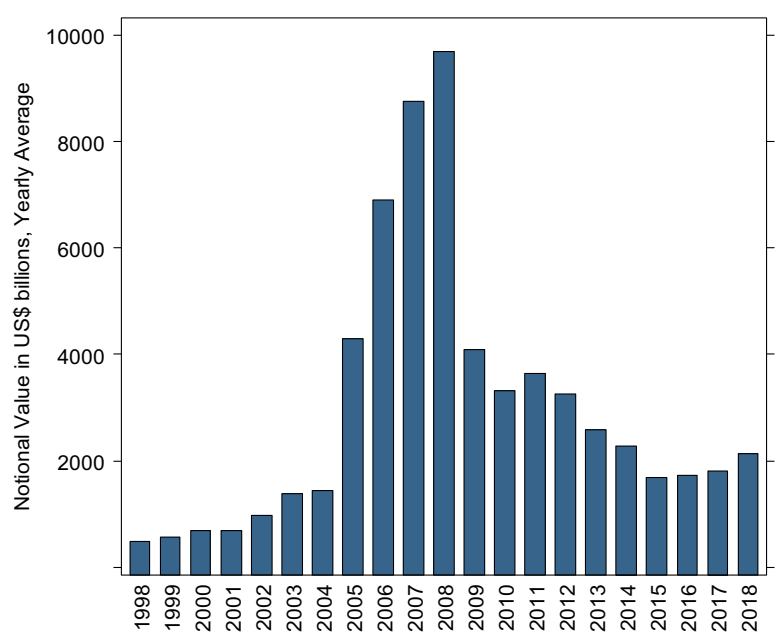

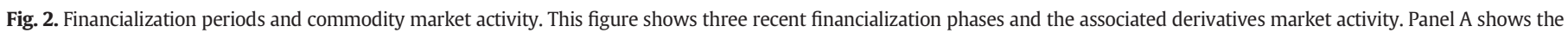

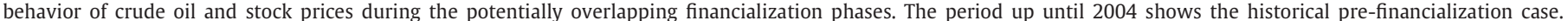

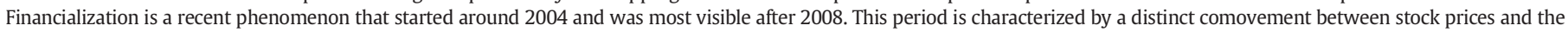

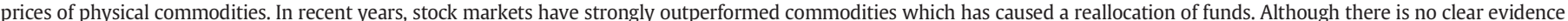

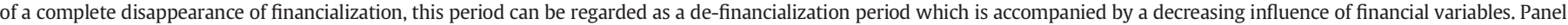

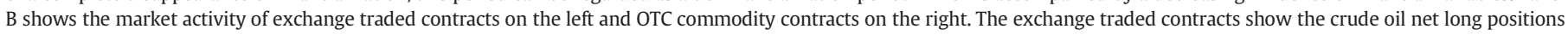

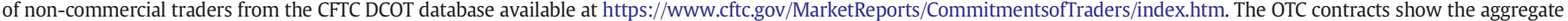
notional value of forwards, options, and swaps for all commodities from the Bank for International Settlements available at https://www.bis.org/statistics/derstats.htm.

\section{Data}

\subsection{A chronology of financialization and de-financialization}

The financialization of commodity markets can be broadly grouped into three phases which are illustrated in Panel A of Fig. 2. The pre-financialization phase represents the historical case of segmented markets: commodities are understood as real physical assets that are uncorrelated to financial assets due to different behavior over the business cycle (Gorton and Rouwenhorst, 2006). The second phase is the financialization period which started around 2004 but did not fully unfold until
$2008 .^{7}$ The impact of financialization on the relationship between crude oil spot prices (black solid line) and stock markets (red solid line) has been well documented in the literature and has caused a significant jump in the comovement between commodity prices and the prices of other financial assets (Tang and Xiong, 2012).

\footnotetext{
7 There exists a certain amount of ambiguity concerning the exact transition date from pre-financialization to financialization. This is visually reflected in partially overlapping time windows in Panel A of Fig. 2. For instance, inflows into commodity markets started to increase in 2004 but the change in price behavior is not observable in the data prior to 2008. The global financial crisis of 2008-2009 interacted and amplified the effects from financialization that were building up in the years before (Adams and Glück, 2015).
} 
For the most recent years, we find evidence for a weakening of the financialization effect in crude oil markets starting in June 2014. However, the behavior of commodities has not reverted to historical levels. We therefore label this period a "de-financialization" period rather than "post-financialization". ${ }^{8}$ The de-financialization of crude oil is likely related to the reported staff reductions in the commodity trading operations at a number of large banks during 2013. According to an article in the Financial Times on August 5, 2013, bank profits from commodity derivatives trading dropped from $\$ 14.1$ billion in 2008 to $\$ 6$ billion in 2012. The June 2014 oil price drop during which crude oil prices dropped by $50 \%$ within a few months have likely prompted further losses and fund withdrawals. The poor performance of the crude oil index together with a spectacular performance of the stock market induced investors to redirect funds from crude oil into the stock market. To illustrate this point, Panel B of Fig. 2 shows the number of exchange traded crude oil contracts on the left, and the notional value of aggregate commodity OTC contracts on the right. The exchange traded market activity decreased sharply after the June 2014 oil price drop but has since increased again, suggesting that the de-financialization observed in the data might be of transitory nature. The OTC contracts for all commodities already peaked in 2008 and has been declining since. The results in Panel B suggest that OTC derivative market activity is much lower today than during the financial crisis and that futures trading activity also temporarily declined in June 2014.

\subsection{Economic fundamental and financial variables}

In this section, we present eight key variables that are used as inputs in our model to explain the variation in the time series of crude oil returns. We focus on crude oil in the following because liquid crude oil futures contracts are highly popular among financial investors but also among ETFs replicating commodity benchmark indices. Summary results for other commodities are presented in Section 5. Four variables represent the universe of fundamental economic variables. These are economic activity, real interest rates, the change in oil inventory levels, and the change in the trade-weighted value of the U.S. dollar. The importance of these variables for commodity markets and their economic mechanism have been thoroughly established in the literature. We will therefore review these variables only briefly. The other four variables are more recent but have been shown to be reliable measures of the financialization phenomenon. They include the CBOE volatility index (VIX), the returns in the S\&P 500, a measure of macroeconomic uncertainty, and the commodity futures risk premium. Their relevance and functioning in commodity markets are less well-known and we will discuss these variables more thoroughly. Our dependent variables are crude oil returns for one set of regressions, and crude oil volatility for another. Returns $r_{t}$ are computed as monthly percentage changes in spot prices $P_{t}: r_{t}=\ln \left(P_{t}\right)-\ln \left(P_{t-1}\right)$. Oil volatility is computed as the square root of the $\operatorname{GARCH}(1,1)$ variance estimated from monthly oil returns: $\sqrt{\sigma_{t}^{2}=\omega+\alpha \cdot \varepsilon_{t-1}^{2}+\beta \cdot \sigma_{t-1}^{2}}$.

Our first variable, Economic Activity, is a key variable for the demand of crude oil. Previous studies find a strong link between income and the demand for oil (Hamilton, 1983, 2009a, 2009b). Our empirical results are in line with these findings. In our model, economic activity can explain a large proportion of the variation in oil returns. In this paper, we use an index of global economic activity proposed by Kilian (2009). This index is particularly suited for our analysis because it measures the component of global real economic activity that drives the demand for industrial commodities. The index is constructed from dry cargo single voyage ocean freight rates and represents global demand for industrial commodities. ${ }^{9}$

\footnotetext{
${ }^{8}$ Similar arguments are presented in Gibbon (2013) who reports results in favor of a slowdown in funds from financial investors rather than a reversal of aggregate investment in commodity markets.

${ }^{9}$ For a more detailed description of the individual steps involved in the construction of that index see Kilian (2009). An updated version of the index can be obtained from the home page of Lutz Kilian at http://www-personal.umich.edu/ lkilian/reaupdate.txt
}

In recent empirical studies, the Kilian measure is an economically strong and statistically significant predictor of the demand for crude oil (see for instance Frankel, 2014) and a good predictor of long-term commodity volatility (Nguyen and Walther, 2018).

Our second economic variable is the real interest rate. Real interest rates have been found to exhibit an inverse relationship with oil prices over time. Major oil price spikes that occurred in the early and late 1970s and during 2008 coincided with low real interest rates (Barsky and Kilian, 2004; Frankel, 2014). On the other hand, the period of low oil prices after 1982 was characterized by high real interest rates. Frankel (2014) describes three mechanisms through which higher interest rates cause a decline in oil prices. First, interest rates affect oil producing firms in their decision about how much oil to pump and how much oil to leave below ground for later extraction. Higher interest rates increase the incentive to extract more today and invest the proceeds at the higher interest rate. The oil supply will therefore increase pushing down oil prices. Second, a higher interest rate increases the financing costs of holding physical storage. Refineries and consumers of oil products therefore consume out of inventories rather than buying new supplies on the spot market. The demand for oil and hence oil prices decline. The third and last mechanism is capital switching. An increase in interest rates makes the investment in bonds more attractive. Financial investors will therefore redirect some of their commodity investments into bonds. The lower demand for commodity investments leads to a fall in prices. We define the real interest rate as the difference between the 3-month U.S. Treasury bill rate and the percentage yearon-year change in the consumer price index.

The third economic variable is the percentage change in oil inventory levels. Oil inventories respond to expectations concerning the future availability of crude oil (Alquist and Kilian, 2010). Commodity consumers respond to fears of possible supply disruptions and stockouts by increasing their physical inventory levels thereby increasing the price (Dvir and Rogoff, 2009). However, empirical studies on the effects of oil inventories are mixed. For instance, Kilian and Murphy (2014) investigate the role of inventories in the variation of oil prices and find that the relationship is rather unstable. Our empirical results are in line with this finding. The percentage change in inventory levels explains only a small part of the variation in oil returns and volatility. Still, measures of oil inventories are frequently used in empirical work and we decided to include the inventory variable for completeness.

The fourth and last fundamental economic variable in our model is the percentage change in the U.S. dollar exchange rate. Crude oil is traded in world markets and is denominated in U.S. dollars. An appreciation of the dollar means higher costs for oil importing countries. If the dollar appreciates, importing countries will ask for lower oil prices in order to be compensated for an exchange rate loss. At the same time, oil exporting countries receive additional exchange rate profits when paid in dollars and have some scope for reducing oil prices. Oil prices and the dollar exchange rate are therefore inversely related. A number of empirical studies confirm the importance of the U.S. dollar exchange rate for explaining crude oil prices, both in the short run (Amano and van Norden, 1998; Sadorsky, 2000), and in the long run (Zhang et al., 2008). Our measure for the dollar exchange rate is the U.S. trade weighted value of the U.S. dollar against major currencies.

Fig. 3 shows the monthly observations for our economic variables from January 1990 to January 2019. The Kilian index shows high levels of economic activity in the first half of the 2000s, which corresponds to a price boom for many commodities. In the years following the Lehman Brothers default, economic activity decreases reflecting the impact of the great recession. Real Interest rates are declining throughout our sample and are negative for later years. Although some studies argue that the financialization of commodity markets started in 2004, more recent empirical papers find that the Lehman Brothers bankruptcy marks the beginning of a fundamental change in the behavior of commodities (Adams and Glück, 2015). We therefore label the period up to August 2008 as 
(a) Economic Activity (Kilian, 2009)

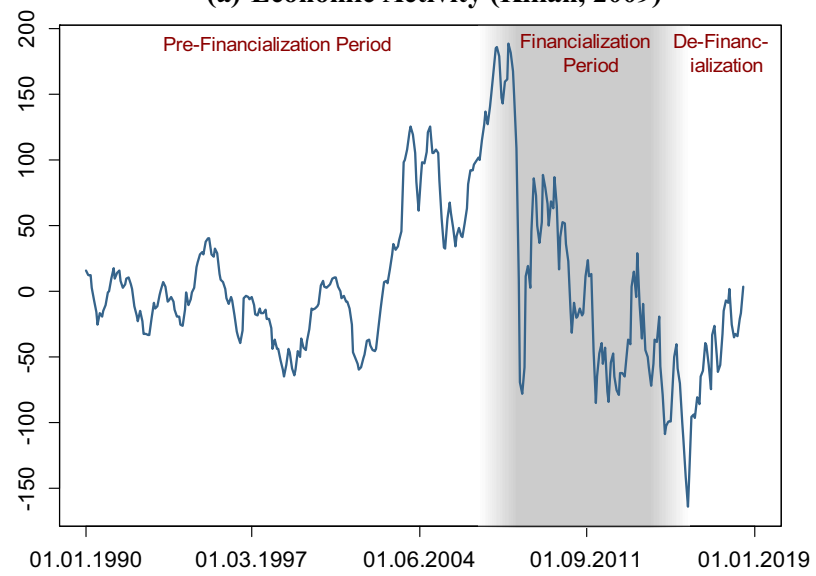

(c) $\Delta$ (Oil Inventory Levels)

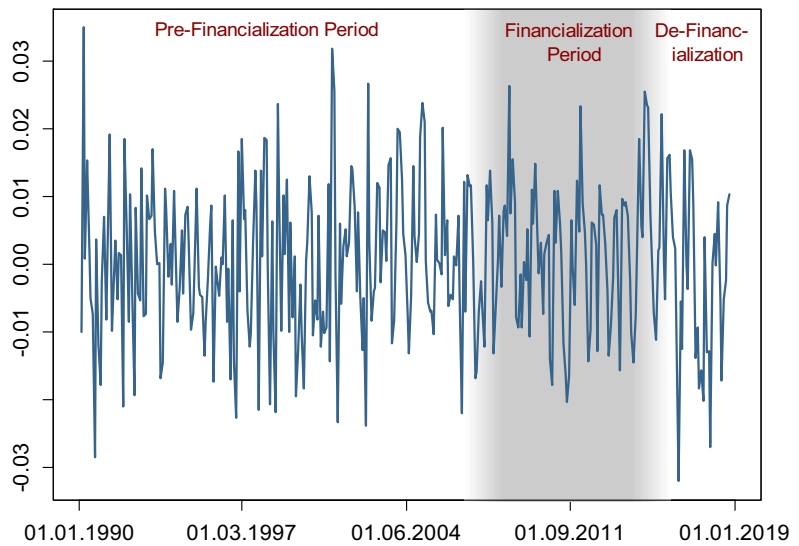

(b) Real 3-Month Treasury Bill Rate

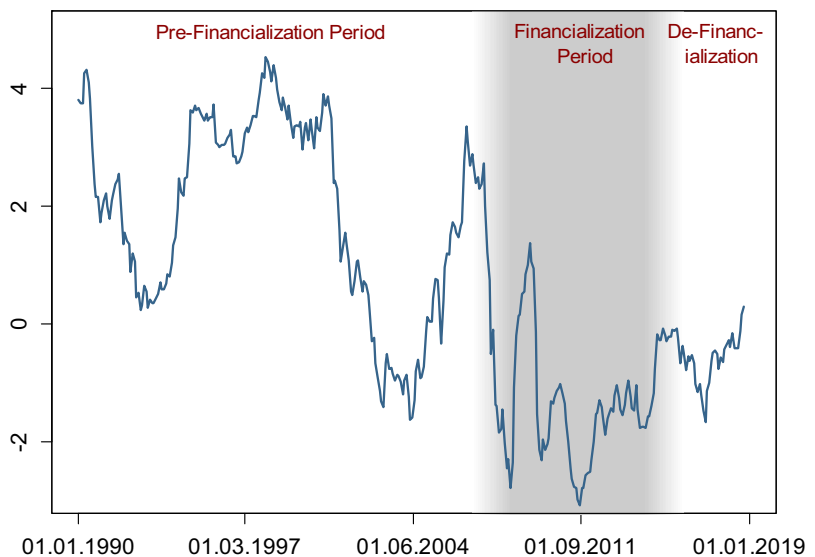

(d) $\Delta$ (Exchange Rate)

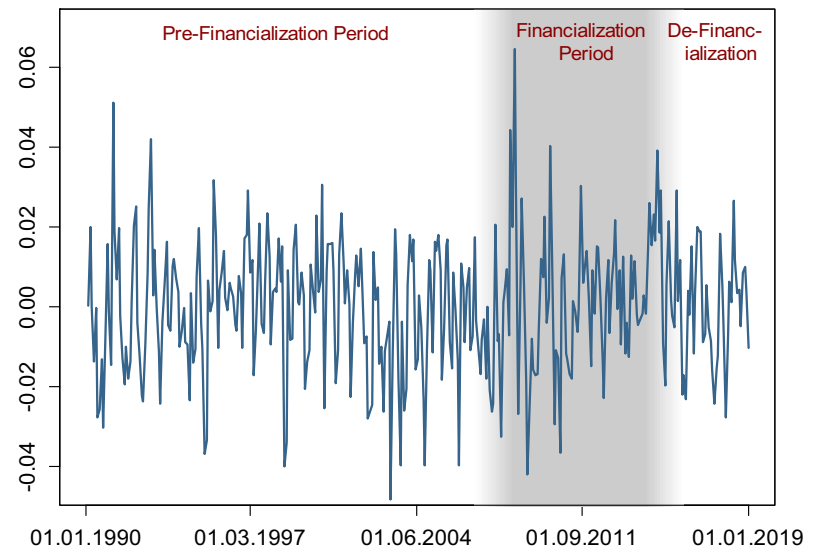

Fig. 3. Variables measuring the economic fundamentals of commodity markets.

"pre-financialization period" and the period starting in September 2008 at the "financialization period".

The first of the four considered financialization variables is the VIX volatility index. The VIX measures the implied volatility of S\&P 500 index options and has proved a strong proxy for investors' attitude towards risk (IMF, 2004; Hartelius et al., 2008; Sari et al., 2011). The VIX is also used as a proxy for the risk absorption capacity of financial traders in commodity markets. Cheng et al. (2015) show that high levels of the VIX index reverse the flows from financial investors into commodity markets, thereby depressing prices. Silvennoinen and Thorp (2013) show that the integration between commodities and financial markets is higher with increasing VIX levels. In our paper, we find that the VIX has become an important variable in explaining the volatility in crude oil returns.

The second financialization variable is the return in the SEP 500 index. The S\&P 500 is a key variable in our analysis. Financialization describes the phenomenon that something becomes more "finance like" and hence can be explained by financial assets like stock price movements. The degree to which oil prices can be explained by stock market returns therefore gives a direct indication of the intensity of the financialization process. Although studies that were already published in the pre-financialization period find a link between stock markets and crude oil, the magnitude of this link has increased dramatically since the beginning of the financialization period (Aloui and Jammazi, 2009; Bahrn and Nikolovann, 2010; Lee and Chiou, 2011).

The variable Macroeconomic Uncertainty causes informational frictions in commodity markets and can confuse market participants into a behavior that amplifies the speculative effects of financialization (Cheng and Xiong, 2014). The extreme oil price rise in the first half of 2008 when the WTI price increased by more than $50 \%$ followed by an equally severe fall in prices in 2009 needs to be interpreted in this light. In this paper, we test for the impact of macroeconomic uncertainty on crude oil prices using a recent measure proposed by Jurado et al. (2015), henceforth denoted as "JLN". This measure is based on the idea that what matters for an indicator of economic uncertainty is whether the economy has become more or less predictable and, therefore, more or less uncertain. This view differs from traditional measures which tend to be based on the idea whether particular economic indicators have become more or less variable. ${ }^{10}$ The JLN uncertainty measure is estimated as the conditional volatility of the prediction error of an economic indicator, thus measuring the variability in the unforecastable components of a series.

$\mathcal{U}_{j t}(h) \equiv \sqrt{E\left[\left(y_{t+h}-E\left[y_{t+h} \mid I_{t}\right]\right)^{2} \mid I_{t}\right]}$

where $\mathcal{U}_{j t}(h)$ is the uncertainty of variable $j$ at time $t$ with forecast horizon $h$. The macroeconomic uncertainty is then computed by taking the average over more than 130 economic indicators such as industrial production, employment, and hours worked.

\footnotetext{
${ }^{10}$ In the past, a number of alternative uncertainty measures have been proposed, the most common one being some function of stock market volatility, either estimated from stock prices directly or by the VIX volatility index. However, a measure of financial market volatility is likely to be driven by factors associated with time-varying risk-aversion rather than economic uncertainty (Bekaert et al., 2013). Another popular approach is based on measures of disagreement among professional forecasters (D'Amico and Orphanides, 2008). However, disagreements in survey forecasts could be due to differences in opinion rather than uncertainty (Mankiw et al., 2004).
} 
$\mathcal{U}_{t}(h) \equiv \sum_{j=1}^{N} w_{j} \mathcal{U}_{j t}(h)$

Jurado et al. (2015) show that the time-variation in the uncertainty measure in Eq. (5) is quite different from other common alternatives like the VIX index. For instance, significant uncertainty episodes occur less frequently than in other popular measures but when they do occur, they are larger, more persistent, and have a larger negative impact on real activity. ${ }^{11}$

The fourth and last variable that has been used in the literature to model financialization is the Risk Premium. The risk premium is defined as the difference between the spot price that is expected at a future point $T$ and the current futures price with maturity $T$ :

$R P_{t}=E_{t}\left[S_{T}\right]-F_{t, T}$

The risk premium reflects the demand imbalance for commodity futures positions. Commodity producers demand short positions in order to lock in a price at which they can sell their products over the next months. During normal times, they outnumber the demand for futures long positions coming from speculators or arbitrageurs in the market. In the terms of Cheng et al. (2015), commodity producers are initiating the trade and need to pay a risk premium to the market participants who are accommodating the trade. The risk premium is therefore usually positive. If the investment demand from financial investors increases, they can outnumber the commodity producers in which case speculators need to pay a risk premium and producers now become the recipients of that premium. The risk premium turns negative. Using the timevariation in the risk premium therefore allows us to learn about the speculative demand for commodity futures without the need to rely on a direct but noisy position measure. Baumeister and Kilian (2016) compare recent measures of the risk premium and conclude that the risk premium estimation proposed by Hamilton and $\mathrm{Wu}$ (2014) is the most accurate one. In this paper, we follow their recommendation and use an updated version of the Hamilton and $\mathrm{Wu}$ (2014) risk premium. Note that the risk premium needs to fall and turn negative to signal a dominating presence of financial investors in the market. The positive part of the risk premium, in contrast, could be also classified as a fundamental economic variable. In the following, we will interpret the risk premium as a financial variable but note here that this will somewhat overemphasize the effect of financial variables during normal market times.

Fig. 4 shows the monthly observations for our financialization variables from January 1990 to January 2019. The high levels of the volatility index VIX after the Lehman Brothers default in 2008 indicate a period of financial distress. During the same time, the returns of the S\&P 500 index were strongly negative. September 2008 therefore represents a structural change for our financial variables but also for the behavior of commodity prices. The remaining two variables, macroeconomic uncertainty and risk premium, also respond strongly to the events in 2008. Uncertainty about macroeconomic events reached a historical high and the risk premium turns negative. Although investors temporarily reversed their flows into commodities in 2008 , the negative risk premium shows a general imbalance in the number of financial investor money relative to hedging demand. The risk premium has recently turned positive again reflecting the current de-financialization phase.

In Fig. 5 we show sample correlations between all eight key variables driving commodity markets. With a few exceptions, the correlations are close to zero. For instance, the correlation between macroeconomic uncertainty and the VIX index shows a moderate level of 0.58 , which is in line with the argument in Jurado et al. (2015) that the VIX is a measure

\footnotetext{
11 In addition to the macroeconomic uncertainty variable Jurado et al. (2015) also provide a measure of financial uncertainty which has a very similar interpretation to the VIX. If we swap the VIX index with this measure of financial uncertainty we obtain qualitatively similar results.
}

of financial distress and not an indicator of general market uncertainty. The positive correlation between the risk premium and real interest rates can be explained by the capital switching argument: if the returns on bonds are low, investors channel their funds into other assets including commodities, leading to an excess demand for long positions thereby driving down the risk premium. The other correlations are as expected. For instance, if the returns of the S\&P 500 are negative the VIX index will be high. From Fig. 5 we conclude that every variable contains sufficient own variation to justify inclusion into our model.

\section{Empirical results}

In this section, we decompose the total variation of crude oil returns and volatility into three distinctive parts: One part that can be explained by economic fundamental factors, one part that can be explained by financialization variables, and a third, which consists of the unexplained variation. ${ }^{12}$ While decomposing the returns provides information concerning the main drivers of crude oil as an asset, the volatility decomposition reveals the main factors of risk transmission. We show that the relative importance of economic and financial variables changes over time. In particular, the relative importance of financial variables has changed in such a way that crude oil has transformed to a financial asset rather than a real physical asset.

Panel A of Fig. 6 shows the decomposition of the total variation in crude oil returns. The fraction of the total variation that can be explained by movements in economic variables is indicated by green shaded areas, the percentage that can be explained by financial variables is indicated by the red shaded areas. The remaining variation is unexplained. The large share of unexplained variation may be due to omitted factors such as geopolitical changes, synchronized OPEC oil production, and disrupting weather events. At a given point in time, the sum over all green and red shaded areas represents the R-squared from a regression of monthly crude oil returns on our set of explanatory variables. The explanatory variables enter the regression in contemporaneous form for simplicity but lagged variables generate similar results. To obtain time variation, the regression is moved forward in a 5-year rolling window (60 monthly observations). ${ }^{13}$ Two observations follow from Fig. 6: During the pre-financialization period, the contemporaneous variation in our eight regressors explains only a small percentage of the total variation in crude oil returns. After the default of Lehman Brothers, the situation changes dramatically. The same set of regressors now explain almost $60 \%$ of the return variation. Among the fundamental variables, economic activity and the change in the dollar exchange rate explain $10 \%$ and $12 \%$ respectively. Both variables showed higher fluctuations during the financial crisis. The economic activity index moved from positive into negative values within a few months. The dollar exchange rate first appreciated and then fluctuated at a higher volatility in the following years. For instance, the U.S. dollar appreciated against the Euro from $\$ 1.55$ in August 2008 to $\$ 1.26$ three months later. The impulse coming from these two variables is reflected in higher explanatory power during the financialization period. The main drivers behind the variation in oil returns are however the financial variables. In particular, the change in the VIX and the S\&P 500 returns are responsible for $28 \%$ of the total variation. The size of the impact coming from movements in financial markets has not been observed in the past and the recent literature on financialization has meticulously collected empirical evidence

\footnotetext{
12 In Appendix A of the paper, we also present a decomposition of real crude oil prices. However, price levels are subject to a number of structural breaks that need to be accommodated in the R-squared decomposition. Because these structural breaks have diluting effects on our analysis, our empirical part focuses on returns and volatility.

13 The 5-year window is to some extent arbitrary but reflects the trade-off between using a large window in which important events are oversmoothed and using a smaller window in which the number of observations is small and the time-variation in the Rsquared is erratic. Although our results are quite robust to shortening or extending the window by one year, our empirical findings are most prominent in the 5-year rolling window.
} 
(a) VIX

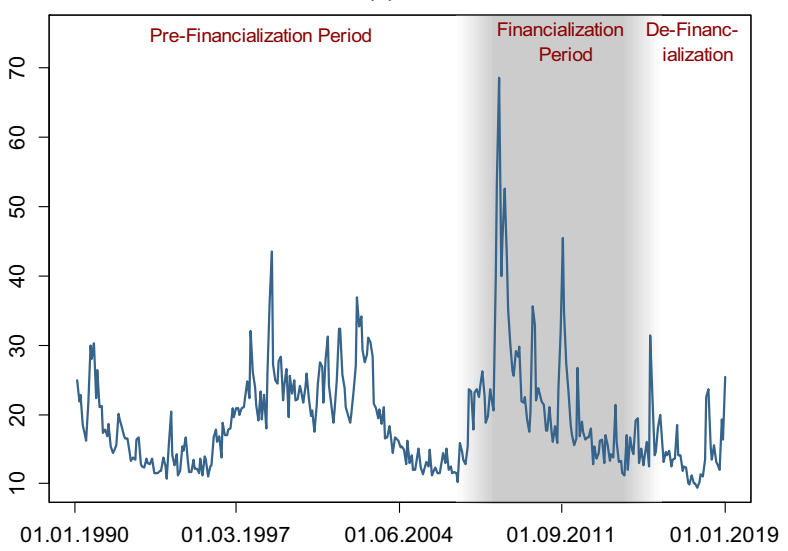

(c) Macroeconomic Uncertainty (Jurado et. al, 2015)

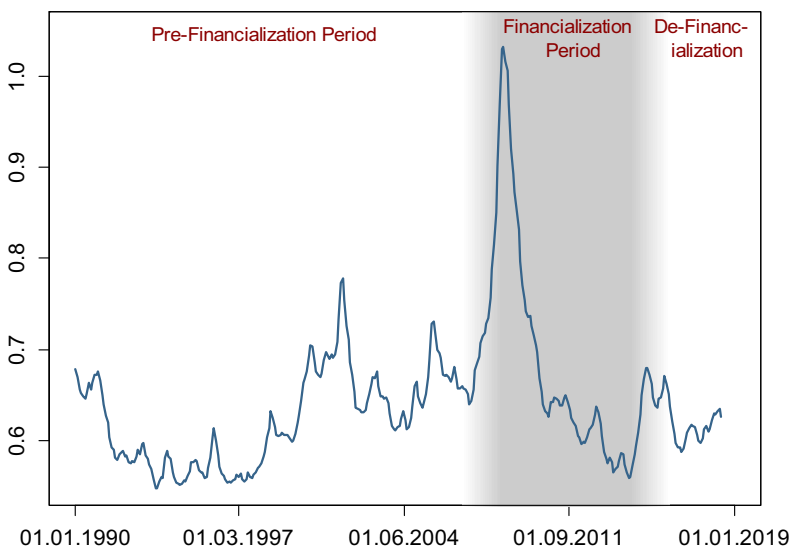

(b) $\triangle S \& P 500$

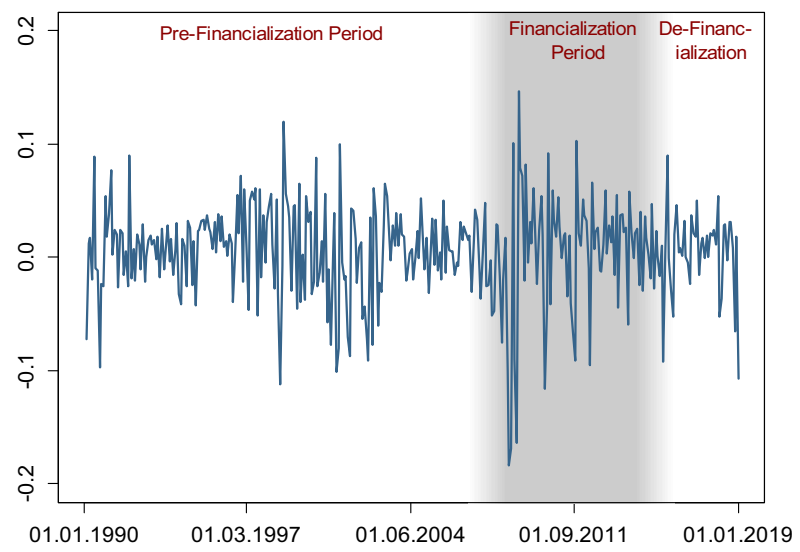

(d) Risk Premium (Hamilton and $\mathrm{Wu}, 2014)$

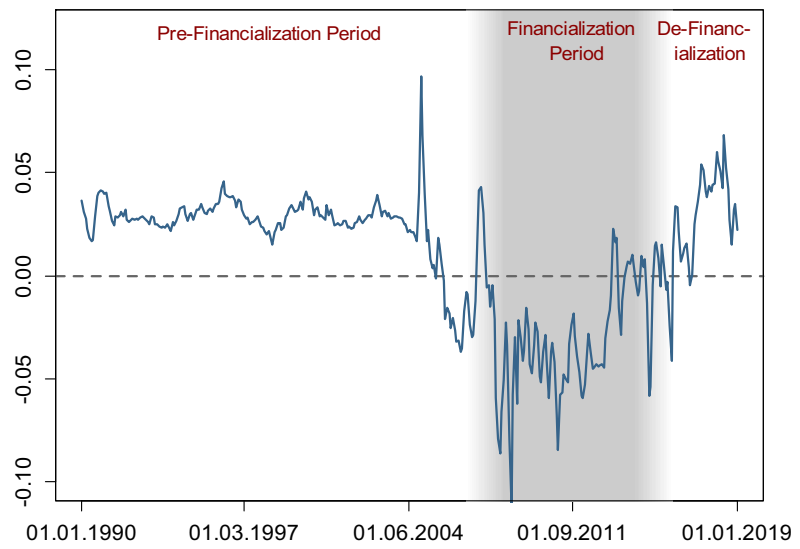

Fig. 4. Variables measuring the financialization of commodity markets.

that this is the result of large investments from financial traders (Henderson et al., 2015; Cheng et al., 2015).

To illustrate this point, the average fraction explained by each set of variables is shown in Panel B of Fig. 6. Since the beginning of the financialization period, the financial variables dominate the economic fundamental variables by a significant amount. While traditional fundamental variables remain relevant for predicting crude oil returns, recent financial variables have come to predict the majority of the return variation. From this finding, we conclude that the behavior of crude oil has become more similar to that of financial assets like stocks rather than traditional economic demand and supply drivers. The most recent years starting after the oil price drop in June 2014 show a partial reversal of the financialization effect. Although our aim is not to overemphasize this point, early empirical and anecdotal evidence (see Section 1) suggests that this period is likely to be a transitory phenomenon, so that we label this recent period a "de-financialization" rather than a "post-financialization" period.

In Fig. 7, we extend our analysis to the volatility of oil returns. Panel A shows that economic activity and the interest rate are the main economic variables driving crude oil volatility. Among the set of financial variables, stock market volatility (VIX), macroeconomic uncertainty, and the futures risk premium can explain the majority of oil volatility. Similar to our previous analysis, the financial variables become the dominant drivers behind the crude oil variation. Panel B of Fig. 7 shows that during the financialization period, $56 \%$ of the total variation in oil volatility can be explained by financial variables while only $21 \%$ can be explained by fundamental economic variables. Our empirical findings suggest that financial variables are not only responsible for explaining crude oil return behavior but also for the transmission of risk to crude oil markets. ${ }^{14}$ Our findings are in line with Qadan and Nama (2018) who approximate volatility of investor sentiment by the VIX index to show significant spillover effects on the volatility of oil prices.

The size and persistence of our results suggest that financialization fundamentally transformed the nature of the asset class "commodities". The recent period of de-financialization appears to have dampened some of the effects, suggesting that other assets have temporarily attracted investor attention, causing a redirection of investment flows. It is unclear at this point, whether financialization will remain a long-term phenomenon. While Zhang et al. (2017) suggest a temporary occurrence, Bianchi et al. (2020) argue in favor of a long-term effect.

\section{Model extensions and robustness}

In this section, we aim to address a number of issues that emerge in the context of our empirical setup. First, we show that the empirical findings that we reported earlier for crude oil can also be confirmed for a number of other important commodities. Second, we show that commodities that are not part of popular commodity indices are not driven by financial variables and do not behave differently during the

\footnotetext{
14 The unusual high explanatory power of financial variables at the beginning of our sample is likely due to the aftermath of the first Iraq (1990-1991) war that remains in the five-year rolling window until around 1996. Since the war generated uncertainty about future oil supply, the explanatory power only materialized in the decomposition of volatility in Fig. 7, but not in the return decomposition in Fig. 6.
} 


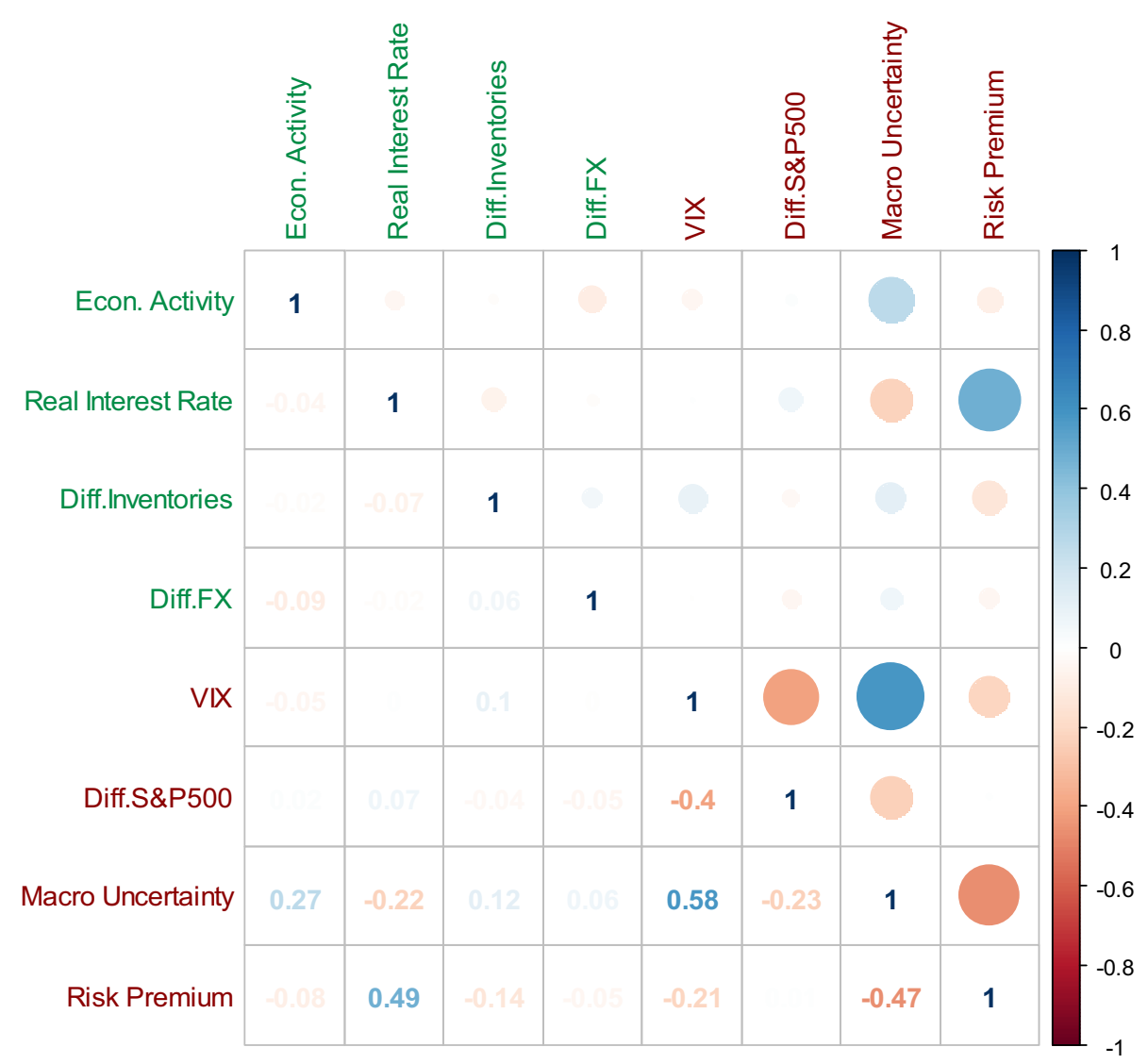

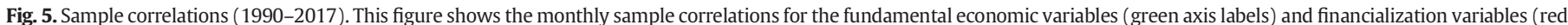

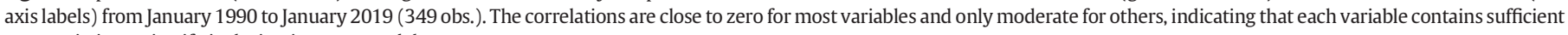
own variation to justify inclusion into our model.

financialization period. Third, we use three stock indices in a placebo test to confirm that stocks, unlike commodities, are always driven by financial variables and the financialization period is not different than other time periods. Our final extension examines whether our results are driven by the functional form of the regression setup and whether nonlinearities play any role in the decomposition of the R-squared.

Fig. 8 shows the decomposition of the regression R-squared for corn, gold, copper, and heating oil. The results for crude oil are repeated for comparison. The choice is motivated by the fact that these commodities have been shown to be affected by financialization in previous studies (e.g. Tang and Xiong, 2012; Adams and Glück, 2015). Panel A on the left shows the decomposition of returns, while Panel B on the right shows the decomposition of volatility. Two results follow from this graph. First, financial variables are generally better at explaining the variation in volatility than in returns. This may be caused by the 2008-2009 financial crisis, which interacted with financialization and has amplified the effects coming from financial traders that respond to both, margin calls from commodity long positions as well as other financial indicators such as S\&P 500 returns or the VIX (Brunnermeier and Pedersen, 2009). Second, the distinct pattern with generally low explanatory power during the pre-financialization period, massive, often dominating explanatory power of financial variables during the financialization period, and somewhat diminished effects during the recent de-financialization years is not unique to crude oil markets but can be also confirmed for heating oil, corn, gold, and copper. The observations from Fig. 8 suggest that the transformation in return and volatility behavior is a general phenomenon that affects the overall commodity market.

If the financialization of commodity markets can be understood as a consequence of the increased investment activity of financial investors, we would expect commodities that are not part of popular commodity indices such as the S\&P GSCI or the Bloomberg Commodity Index to remain unaffected by the financialization phenomenon. The left graph in Fig. 9 shows the R-squared decomposition for three off-index commodities: orange juice, lumber, and oats. For these commodities, financial variables are not important drivers of the return variation. This finding holds true whether we are in a financialization period or not and supports the notion that inflows from financial investors are a necessary condition to cause the transformation of commodity markets.

The right graph of Fig. 9 shows the R-squared decomposition for three stock indices: the MSCI Europe, the DataStream index of insurance companies, and the DataStream index of commercial banks. Since these indices already represent financial assets, we would expect that financialization is a natural outcome rather than an exception. Decomposing the R-squared confirms that the return variation of financial assets can be almost entirely explained by financial variables whereas economic variables that are important for commodities have no explanatory power. The findings from Fig. 9 indicate that the financialization of commodity markets is not simply a side effect of the financial crisis of 2008 , but instead a phenomenon that is specific for a set of commodities that have been the target of financial investors.

The R-squared decomposition in this paper is based on an OLS regression framework in which the four fundamental variables and the four financial variables enter in a linear form. Since our aim is to measure the importance of the variables in explaining commodity prices, we focus on the R-squared instead of the coefficient estimates. In fact, our empirical strategy does not depend on the interpretation of the regression coefficients and linearity is just a matter of convenience. We can extend our analysis of the explanatory power to include other, more general functional forms. The flexibility of the specification is only limited by the 
A: Relative Importance of Fundamental and Financial Factors

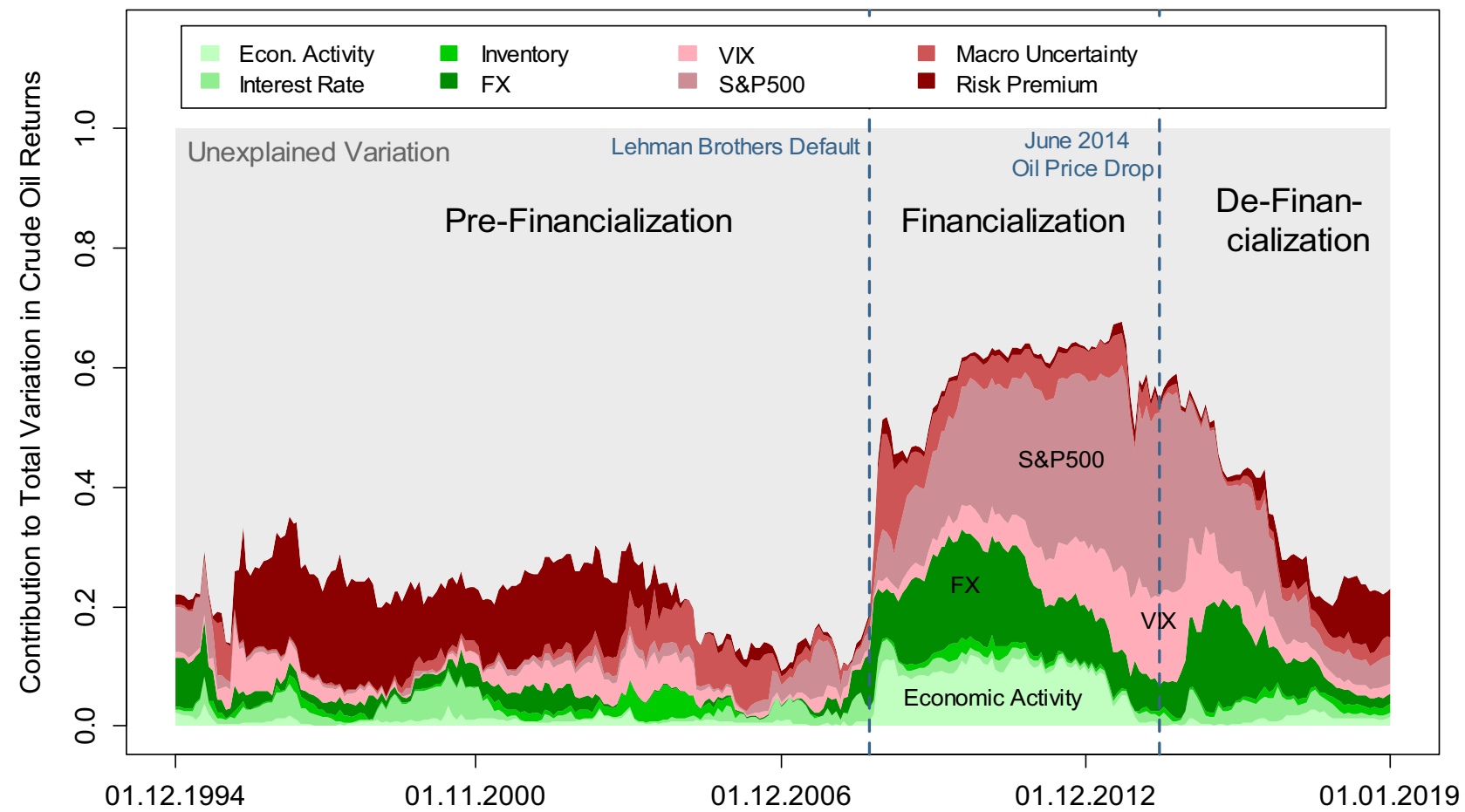

\section{B: Relative Importance Shares in Subsamples}

Pre-Financialization

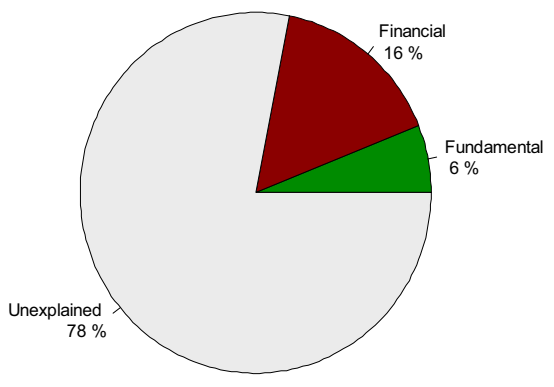

Financialization

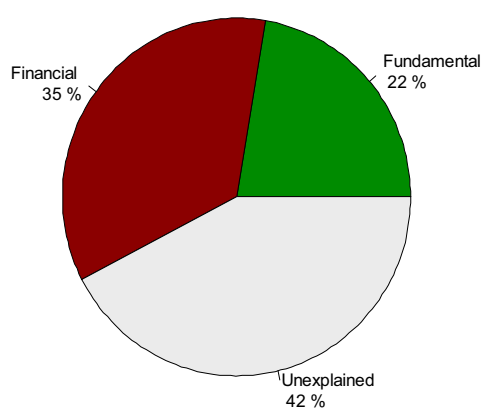

De-Financialization

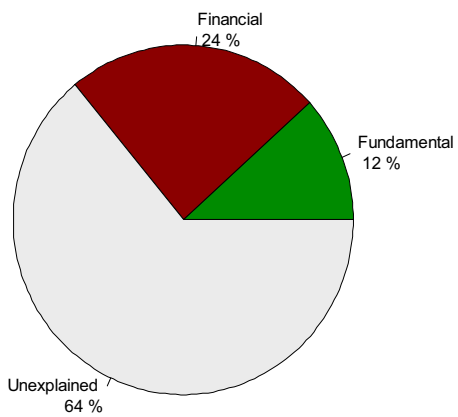

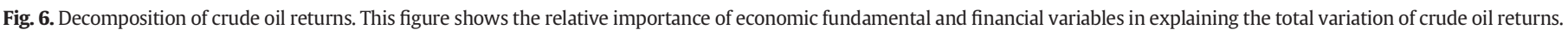

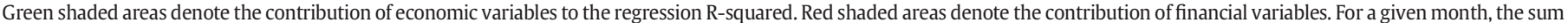
over all shaded areas denotes the overall R-squared of the regression. The remaining area represents the unexplained variation in crude oil returns.X

number of observations, which in our case is 60 monthly observations or five years. Although a fully nonparametric specification with eight explanatory variables is not feasible, we report the results for a parametric translog model (Greene, 2011) which is a secondorder approximation to an unknown functional form:

$$
\ln y=\beta_{0}+\sum_{k=1}^{K} \beta_{k} \ln x_{k}+\frac{1}{2} \sum_{k=1}^{K} \sum_{l=1}^{K} \gamma_{k l} \ln x_{k} \ln x_{l}+\varepsilon
$$

The full specification in Eq. (7) includes all $K=8$ regressors, their squared terms, as well as the complete set of $K \cdot(K-1) / 2=28$ interaction terms. Since our rolling window contains only 60 monthly observations, we propose a more parsimonious specification: We first condense the information inherent in the set of fundamental and financial variables by estimating their first principal components $(P C)$. We then estimate the following parsimonious specification for crude oil returns:

$$
\begin{aligned}
& \text { ret }_{\text {oil }, t}=\beta_{0}+\beta_{1} P C_{\text {fundamental }}+\beta_{2} P C_{\text {financial }}+\beta_{3} P C_{\text {fundamental }}^{2}+ \\
& \beta_{4} P C_{\text {financial }}^{2}+\beta_{5} P C_{\text {fundamental }} \cdot P C_{\text {financial }}
\end{aligned}
$$

The estimating equation for volatility is very similar to that of Eq. (8) but is based on slightly different principal components. ${ }^{15}$ The purpose of the interaction term is to model cross elasticities and can be motivated

\footnotetext{
15 For instance, the four financial variables in the case of crude oil returns include the change in the volatility index, $\triangle V I X$, whereas the level of volatility VIX is used for crude oil volatility.
} 


\section{A: Relative Importance of Fundamental and Financial Factors}

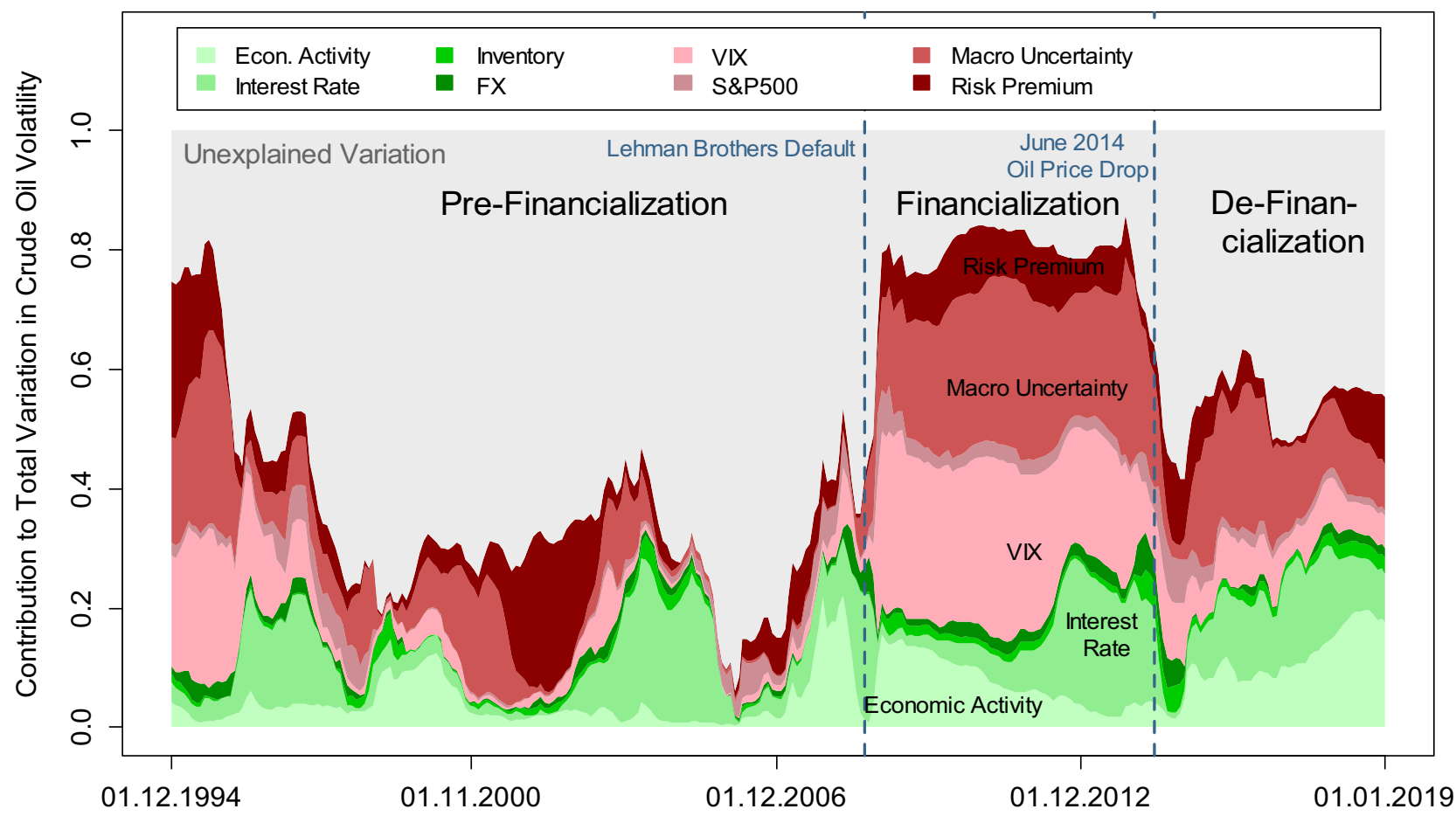

\section{B: Relative Importance Shares in Subsamples}

Pre-Financialization

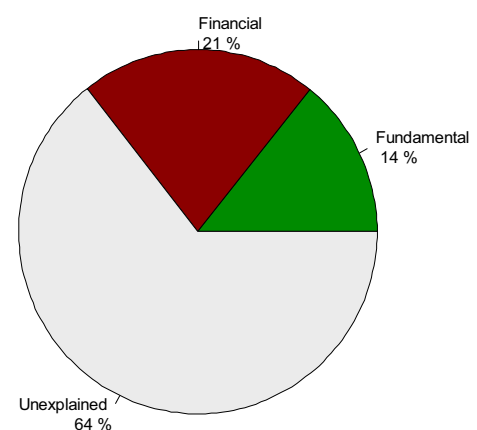

Financialization

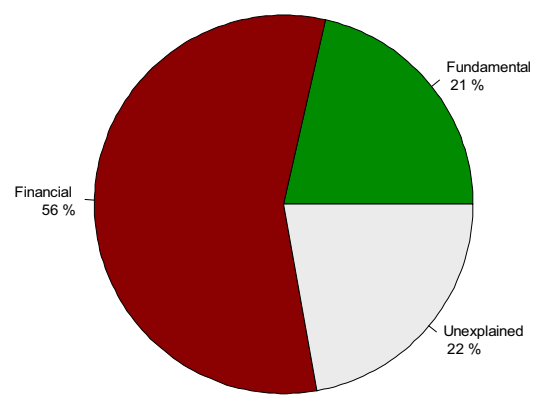

De-Financialization

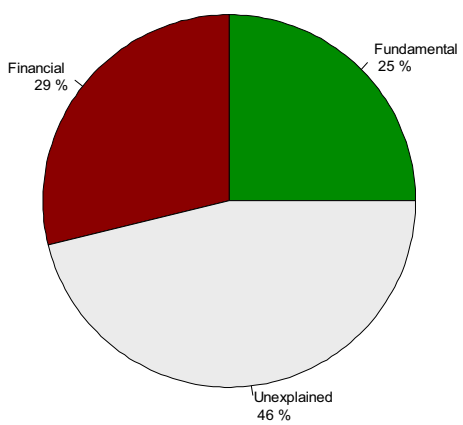

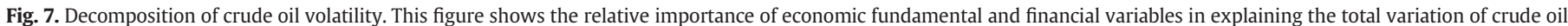

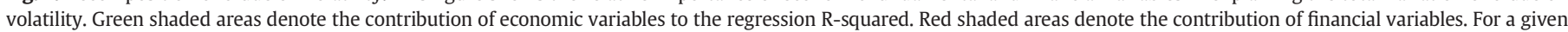

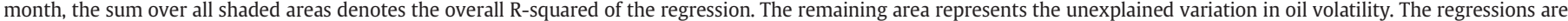
rolled forward in a 5-year rolling window (60 monthly observations).

by the observations that financialization appears to have moderately increased the pro-cyclicality of commodity markets (Valiante and Egenhofer, 2013). ${ }^{16}$ Other specifications that include for instance the first two principal components to represent fundamental and financial variables require a richer model but have very similar results. We therefore focus on the simple specification of Eq. (8).

Fig. 10 shows the time-varying decomposition of R-squared. Panel A shows the decomposition of returns while Panel B shows the

\footnotetext{
16 For instance, Pástor and Veronesi (2013) show that policy uncertainty leads to a greater risk premium during weaker economic conditions. A properly specified regression equation should therefore include an interaction term between policy uncertainty and risk premium.
}

decomposition of volatility. The green shaded areas represent the contribution to R-squared coming from the first principal component of fundamental variables (including its squared term). The red shaded areas represent the impact of the first principal component of financial variables and its squared term. The area shaded in dark-red represents the interaction term, i.e. the additional contribution that is due to changes in the financial component conditional on a given level of the fundamental component. Given the differences in the empirical approach, it is perhaps surprising that the results are very similar to our linear OLS benchmark case. The explanatory power is generally low during the pre-financialization period, the importance of the financial variables is dominant during the financialization period, and seems to be disappearing again during the recent de-financialization years. From Fig. 10, we conclude that our main findings in this paper are 


\section{A: Decomposition of Returns}

\section{Fundamental \\ Financial \\ Unexplained}
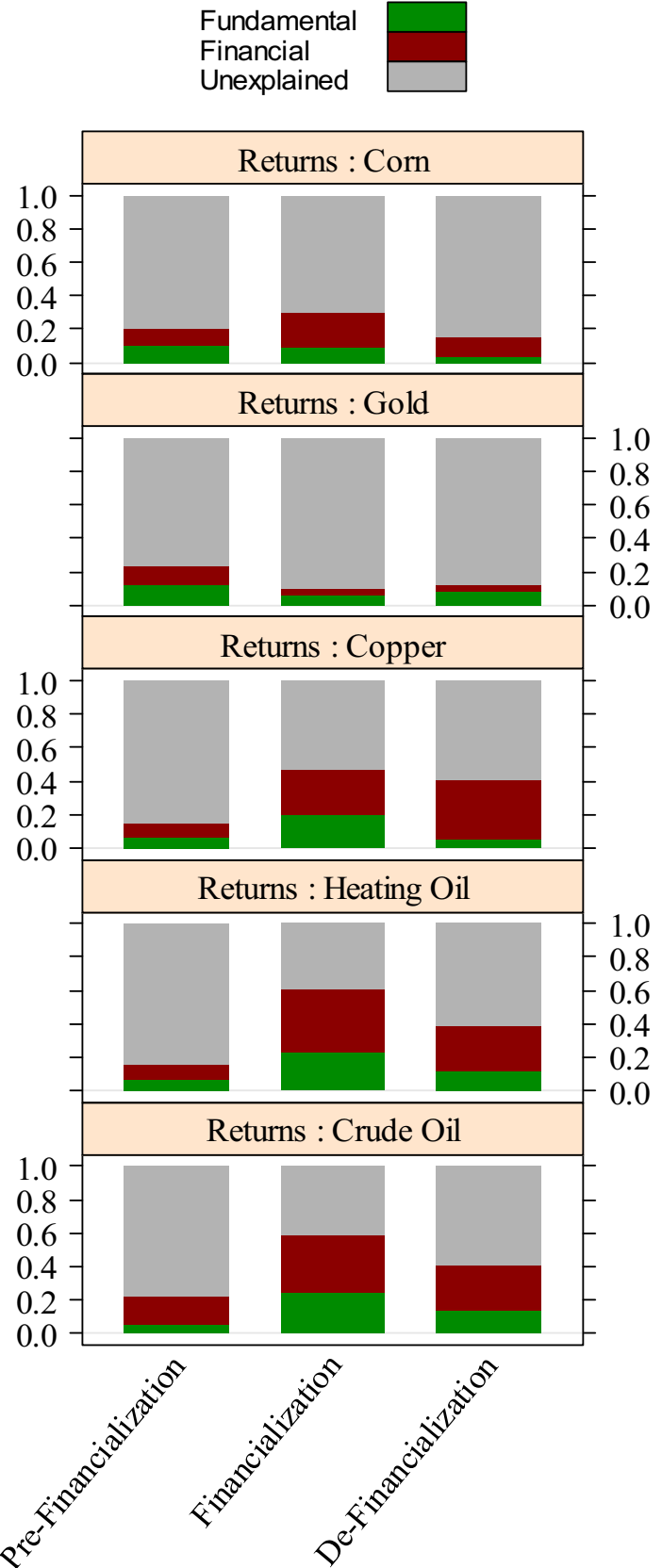

B: Decomposition of Volatility
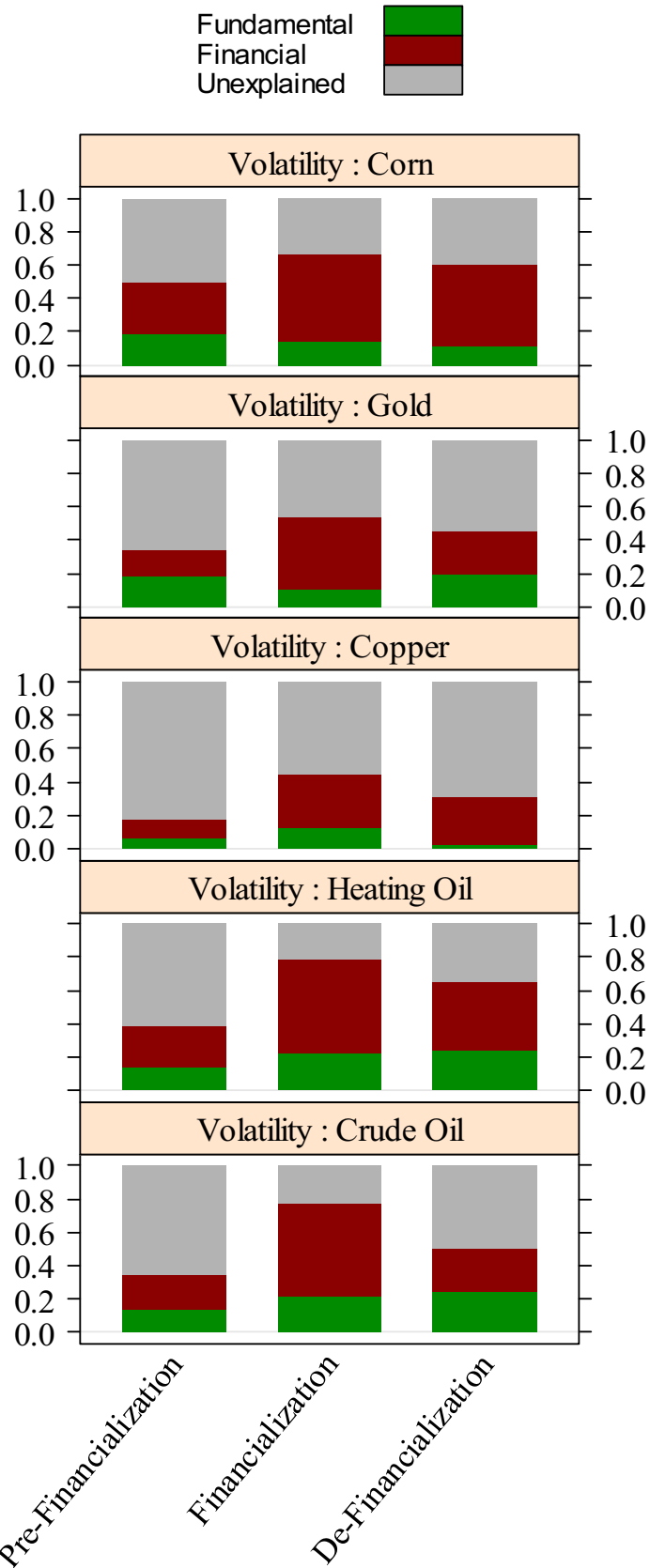

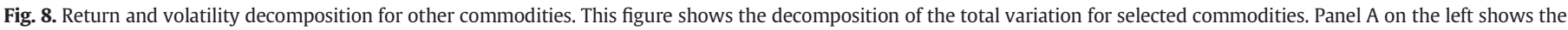

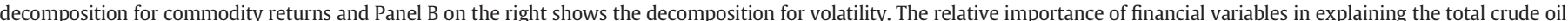

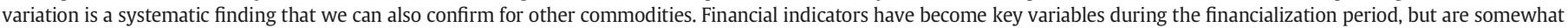

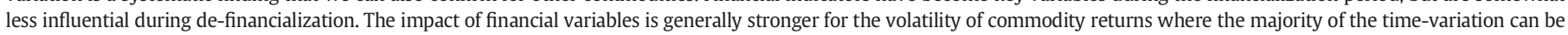
explained by the S\&P 500 index, the VIX volatility index, macroeconomic uncertainty, and the risk premium.

unlikely to be driven by the functional form of the regression specification.

Finally, we test whether our empirical findings also hold when a different methodology is used. Some of the most prominent models in the financialization literature are Vector Autoregressions, which are underlying many of the empirical findings of important contributions such as Kilian (2009) and Kilian and Murphy (2014). We estimate a 9-Equation VAR(1) model based on monthly data for the vector time series $y_{t}$, consisting of crude oil volatility, four lagged economic fundamentals (economic activity, real interest rate, percentage change in oil inventory levels, and percentage change in the U.S. dollar exchange rate) and our four financial variables (VIX volatility index, percentage change in the S\&P 500 index, macroeconomic uncertainty and risk premium):

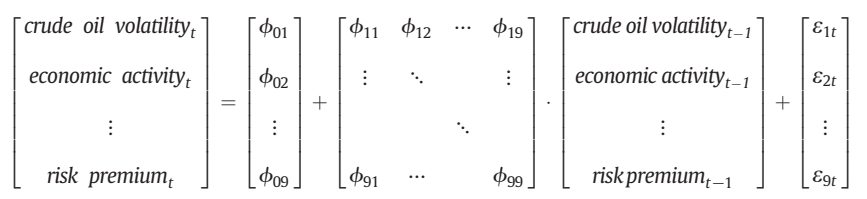




\section{Robustness: Off-Index Commodities}

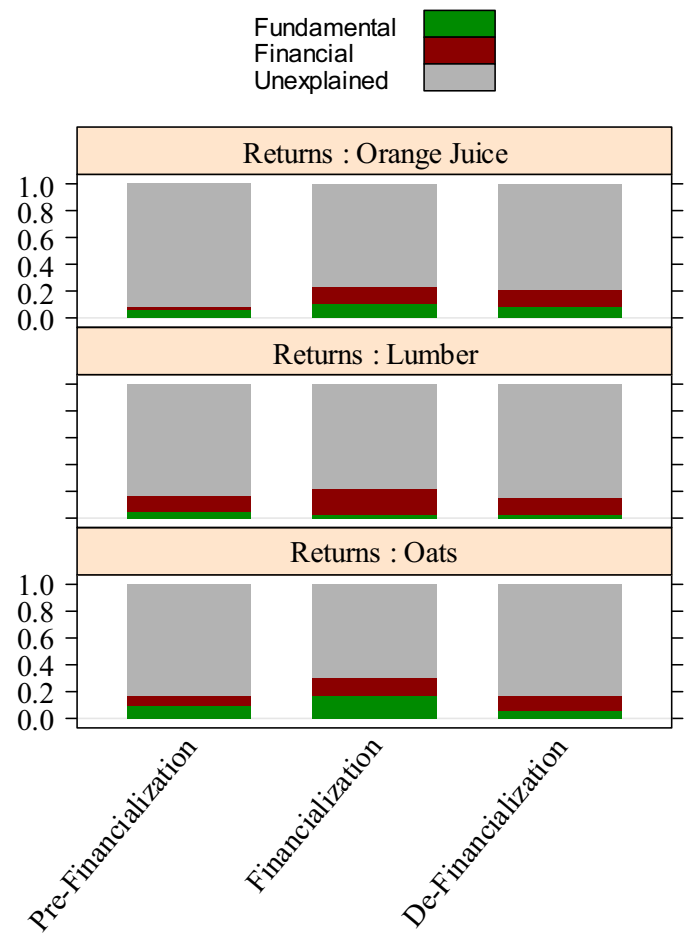

\section{Placebo: Financial Institutions}

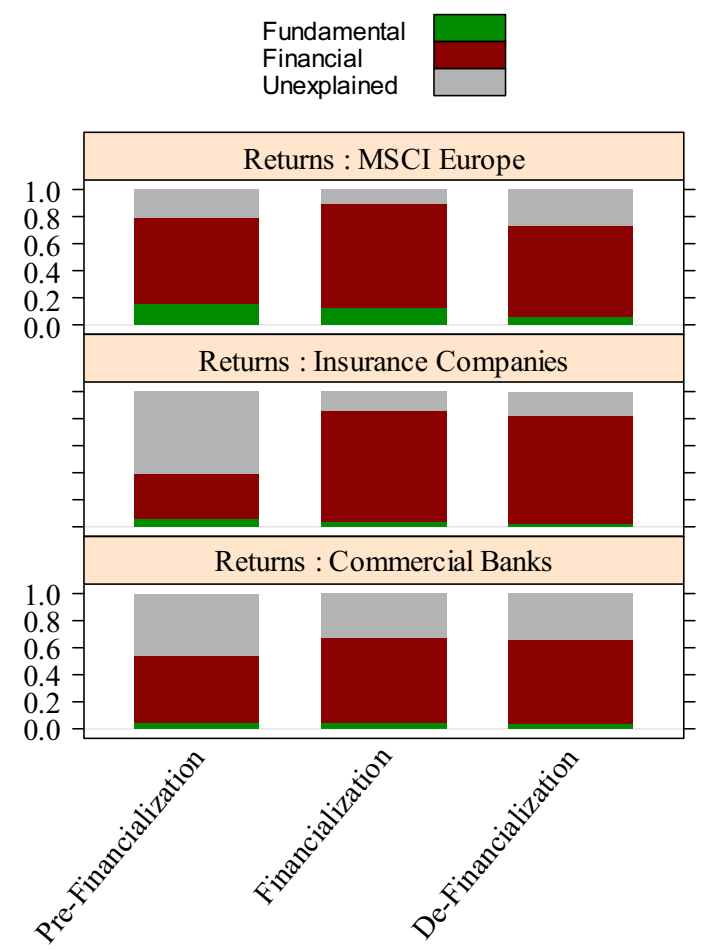

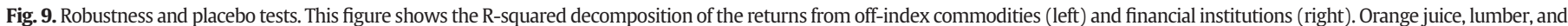

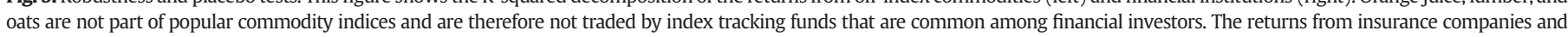

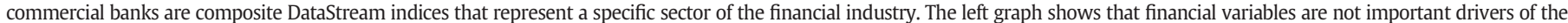
variation of off-index commodities. The right graph shows that financial variables have always been the main explanatory factors of the returns of financial institutions.

or more compactly:

$\mathbf{Y}_{t}=\Phi_{0}+\Phi_{1} \mathbf{Y}_{t-1}+\varepsilon_{t}$

where: $\Phi_{0}$ is a $9 \times 1$ vector representing the intercept terms

$\Phi_{1}$ is a $9 \times 9$ coefficient matrix

$\boldsymbol{\varepsilon}_{t}$ is a $9 \times 1$ vector of serially and mutually uncorrelated innovations.

The model in Eq. (10) requires estimation of $9^{2}+9=90$ parameters. Given the limited number of monthly observations available, we do not expand the model to more lags. For the same reason, we also split the entire sample into three subsamples rather than using a 5-year rolling window: a pre-financialization sample (1990/01-2003/12), a financialization sample (2004/01-2014/06), and a de-financialization sample (2014/ 07-2019/01).

We visualize the contribution of each variable to oil price volatility using the Forecast Error Variance Decomposition (FEVD). Although this approach is different from the R-squared decomposition presented earlier, we obtain qualitatively very similar results. Given the parameter estimates $\hat{\Phi}_{0}$ and $\hat{\Phi}_{1}$ from Eq. (10), we can take the conditional expectation of $\mathbf{Y}_{t+1}$ to obtain the one-step-ahead forecast error:

$\boldsymbol{\varepsilon}_{t+1}=\mathbf{Y}_{t+1}-E_{t}\left(\mathbf{Y}_{t+1}\right)$

Focusing on the $\left\{\mathbf{Y}_{t}\right\}$ sequence, the n-step-ahead forecast error is $\boldsymbol{\varepsilon}_{t}$ ${ }_{+n}=\mathbf{Y}_{t+n}-E_{t}\left(\mathbf{Y}_{t+n}\right)$ and the $\mathrm{n}$-step-ahead forecast error variance of $\mathbf{Y}_{t+n}$ is $\sigma_{\varepsilon \mathrm{t}+n}^{2}$. We analyze the decomposition of the $\sigma_{\varepsilon \mathrm{t}+n}^{2}$ sequence over a forecast period of 10 months.

Panel A of Fig. 11 shows that the forecast error variance of a shock to crude oil volatility during the pre-financialization period is mainly driven by its own past values. Financial and economic variables only have small effects, contributing about $10 \%$ of the variance each. The situation changes dramatically for the financialization period in Panel B. After 10 months, a significant part of the crude oil forecast error variance is explained by macroeconomic uncertainty and the VIX index. The results confirm our previous findings from Section 4 based on Rsquared decomposition. Finally, we find low contributions to the error variance during the de-financialization period in Panel C. This supports our previous observation of an ongoing de-financialization in crude oil markets. From Fig. 11, we conclude that our main empirical findings are not unique to our estimation methodology: using VAR models, we can obtain qualitatively very similar results.

\section{Conclusion}

Financialization describes the increasing dominance of financial actors, markets, and practices, resulting in a structural transformation of the economy (Aalbers, 2016). The dominating view in the general finance literature is that financialization has adverse effects and can replace economic drivers of housing demand (Aalbers, 2016), crowd out investments in machinery and equipment of non-financial firms (Tori and Onaran, 2017), and lead to premature de-industrialization in developing countries (Whittaker, 2017). In this paper, we investigate the relatively recent financialization of commodity markets. In the general finance literature, the transformation of the economy is measured by the size of the financial sector as a fraction of overall production (see for instance Fasianos et al., 2018). We present a similar approach that examines the fraction of commodity prices that can be explained by financial variables. Our empirical findings suggest that the transformation of the commodity market has been particularly disruptive across 


\section{A: Decomposition of Crude Oil Returns}

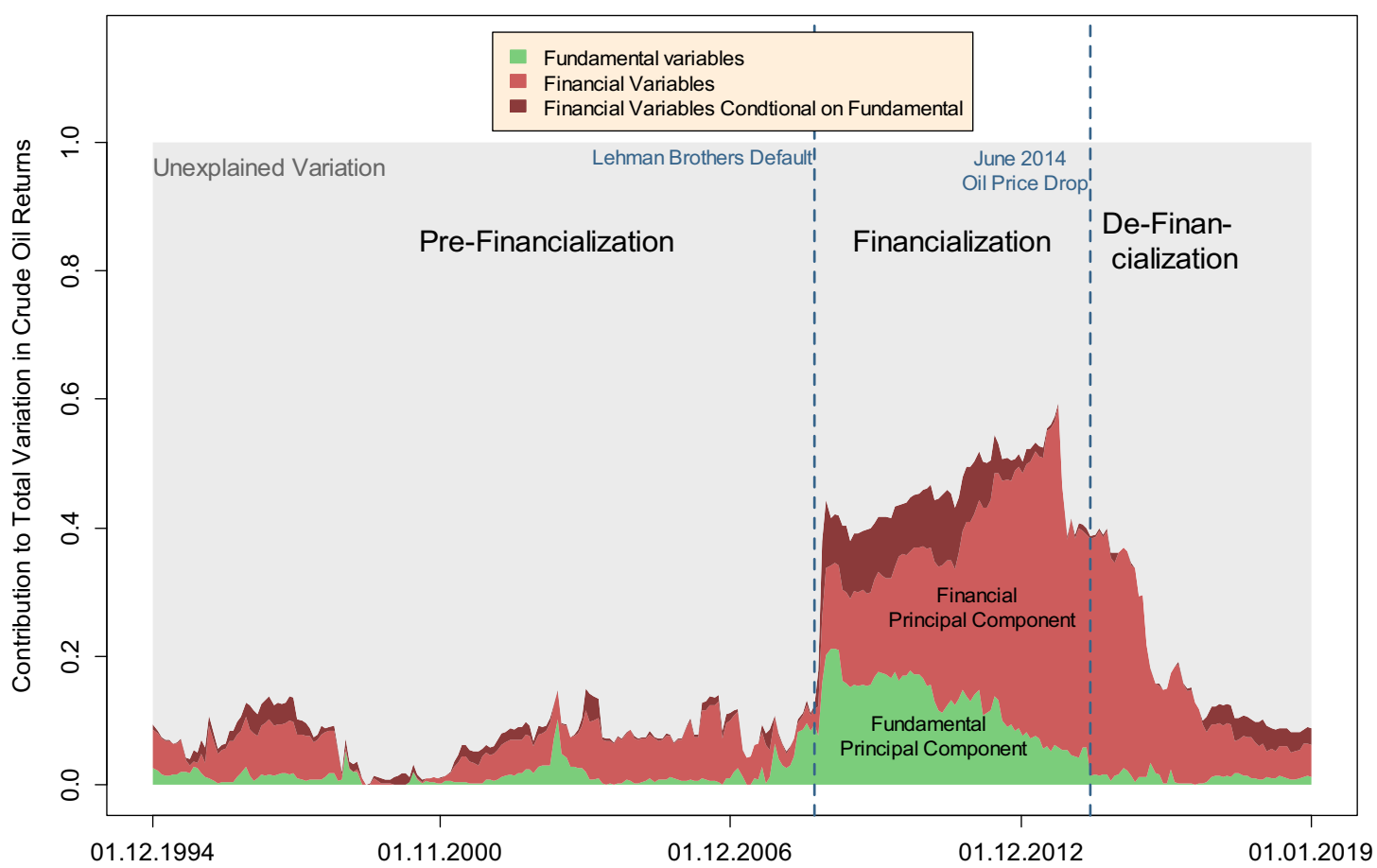

\section{B: Decomposition of Crude Oil Volatility}

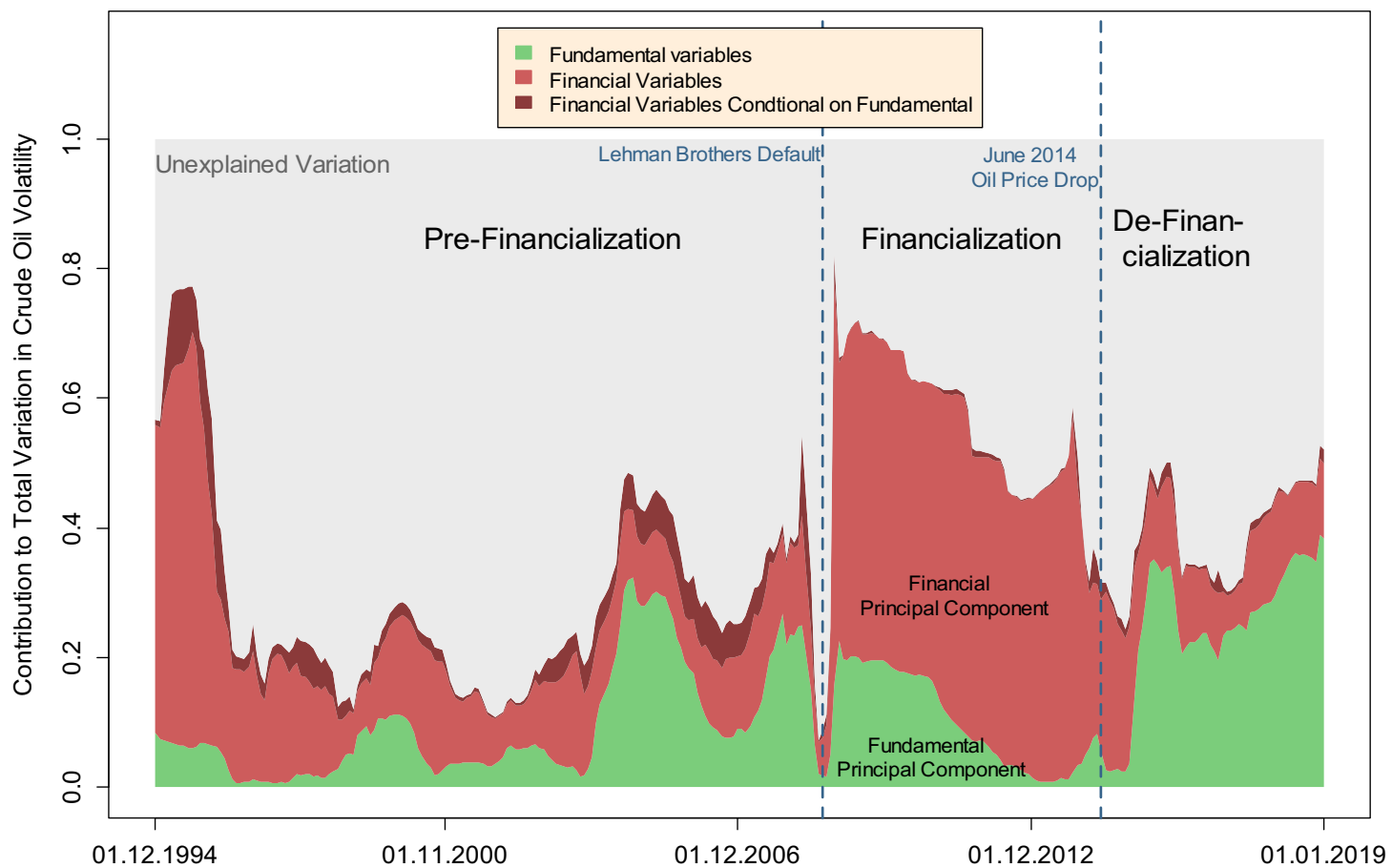

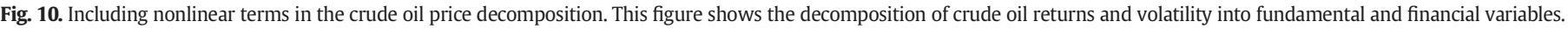

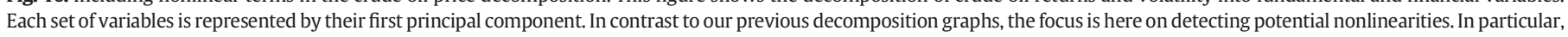

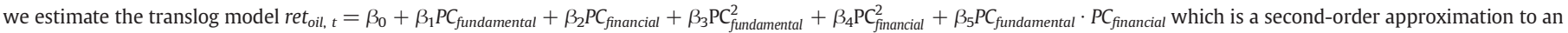
unknown functional form (Greene, 2011).

a wide range of commodities, including energy, metals, and agricultural products. As a consequence, commodity price behavior has changed from a physical real asset to that of a financial asset. Although our results are silent about the exact economic mechanism behind these changes, our findings have important implications: Under financialization, commodities are unlikely to provide effective diversification benefits in a mixed-asset portfolio, the prices of daily food products and energy costs are likely to fluctuate with changes in crude oil markets, and the 


\section{A: Pre-Financialization period (January 1990 - December 2003)}

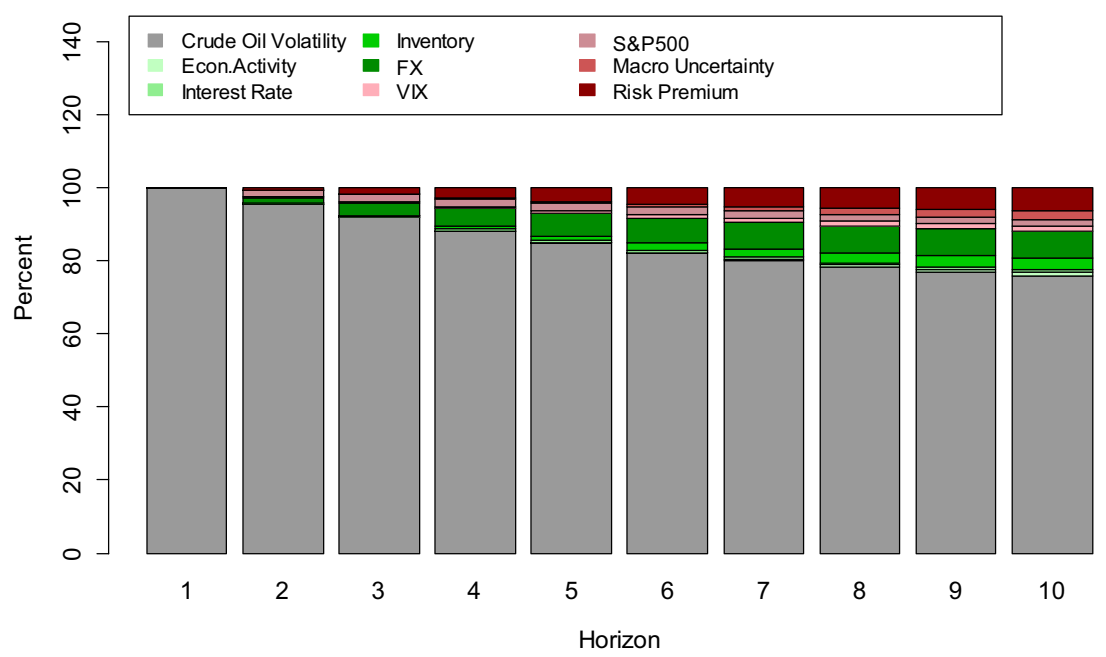

B: Financialization period (January 2004 - June 2014)

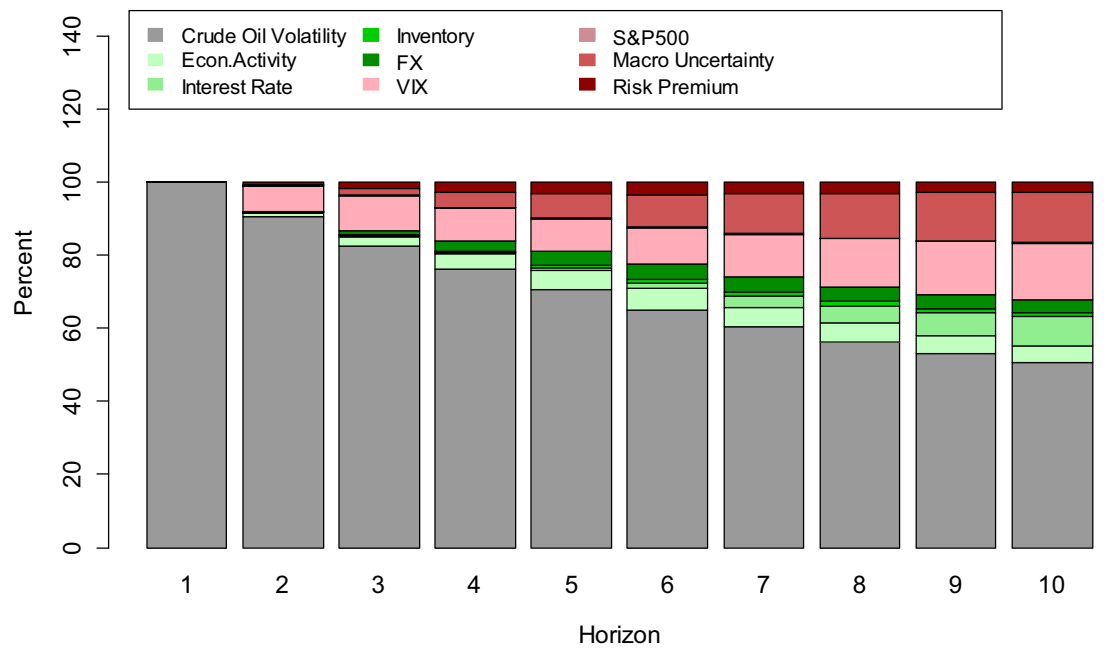

C: De-Financialization period (July 2014 - January 2019)

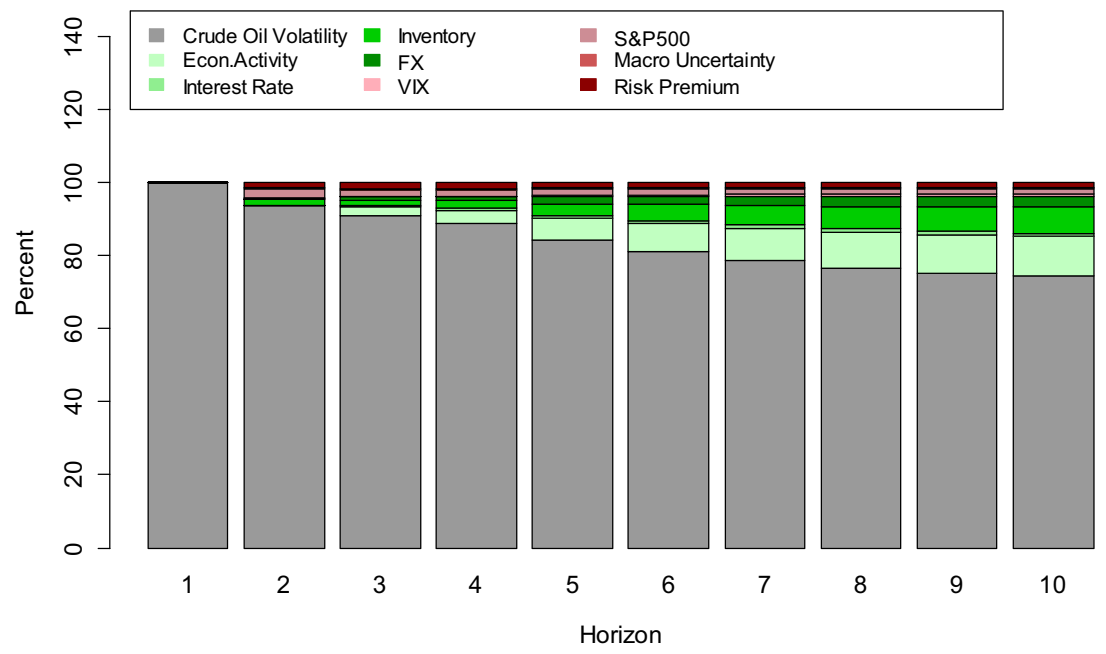

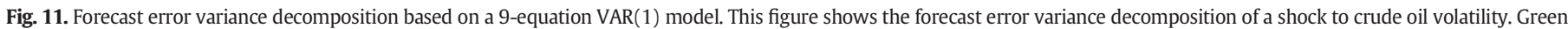

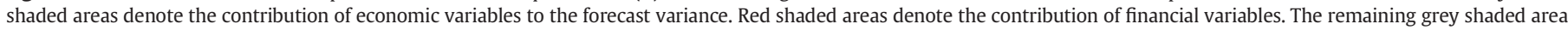

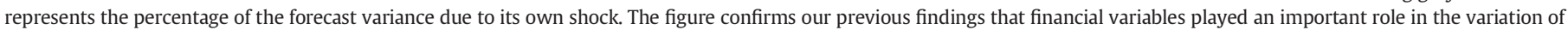
crude oil volatility. 
forecast of future commodity prices based on traditional economic indicators becomes imprecise.

However, we also find that commodities have recently entered into a period of de-financialization during which the dominance of financial variables appears to have extenuated. This finding is in line with the general financialization literature which reports that financialization has gone through several cycles over the last 100 years (Fasianos et al., 2018). Although it is presently too early to know with certainty, anecdotal evidence from the industry suggests that demand for commodity derivatives has been rising again since 2018 so that the current de-financialization is likely to be a temporary phenomenon rather than a symptom for a return to historical norms.

\section{Appendix A. Unit root tests and real crude oil prices}

In this appendix, we discuss the possibility to extend our analysis to the (real) prices of crude oil. Most studies investigate returns or the volatility of commodity returns to avoid problems arising from non-stationarity in prices. However, if carefully implemented, one can apply the analysis in our paper also to oil price levels. In the following, we will briefly explain the methodological approach and discuss why the empirical evidence for prices is weaker.
Conventional unit root tests fail to reject the null hypothesis in the presence of structural breaks. Perron (1989) showed that many macroeconomic time series can be found to be (trend) stationary once exogenous shocks such as financial crises are accounted for. In the Perron (1989) approach, structural breaks are interpreted as exogenous shocks that are identified by visual inspection of the data. Zivot and Andrews (1992) extend this idea by proposing a procedure that tests for the occurrence of breaks at unknown points in time. These breaks could occur in form of a level shift, $D U$ or a change in the slope of the time series, DT. The oil price series used in this paper appears to suffer from both types of structural breaks: after a period of slightly declining growth during the 1990s, oil prices moved on a distinct upward trajectory starting in 1998. The growth path includes the pronounced 2008-2009 oil price boom and bust and loses its momentum in the first half of 2014 where it fluctuates around a price of $\$ 110$ per barrel. The year 1998 therefore marks a change in the trend of oil prices. The June 2014 oil price drop marks a second change which appears to have affected both, the trend and the level of oil prices: Within a few months, oil prices dropped to $\$ 50$ and below. The Zivot-Andrews test identifies a structural break in the level and trend of oil prices in September 2014 which is close to the widely noted oil price drop that started in June 2014. The ZivotAndrews test is limited to detect one structural break. In order to detect

Panel A: Structural Breaks in the Levels of Real Crude Oil Prices

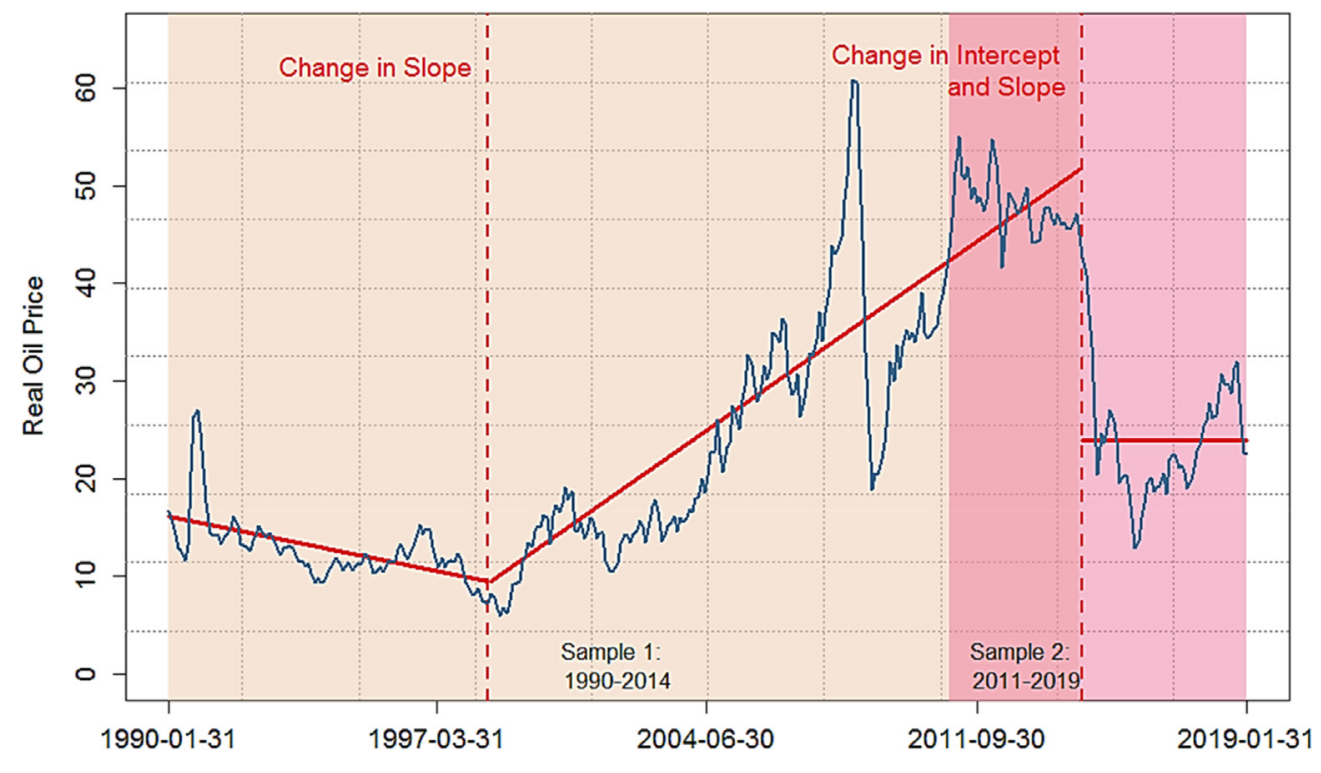

Panel B: Standard Unit Root and Zivot-Andrews (1992) Test Statistics

\begin{tabular}{|c|c|c|c|}
\hline \multicolumn{2}{|c|}{ Sample $1(1990-2014)$} & \multicolumn{2}{|c|}{ Sample $2(2011-2019)$} \\
\hline ADF & -2.34 & ADF & -1.36 \\
\hline PP & $-19.37^{*}$ & PP & -7.04 \\
\hline $\mathbf{Z A}$ & $-5.18^{* * *}$ & $\mathbf{Z A}$ & $-4.51^{*}$ \\
\hline
\end{tabular}

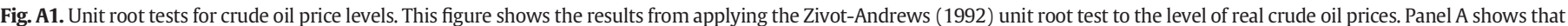

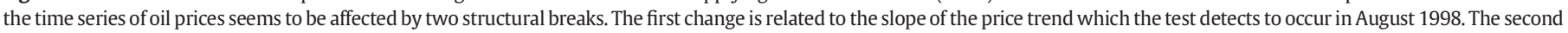

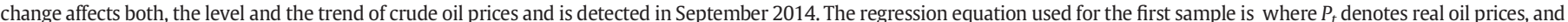

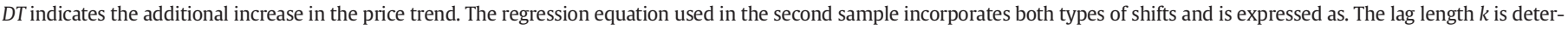

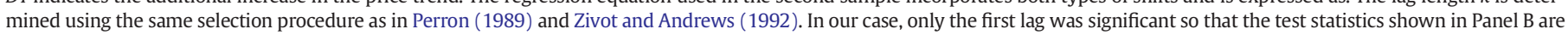
based on $k=1$. 
the second break in 2014 we apply the test to two subsamples of our data. Sample 1 ranges from January 1990 to June 2014. Sample 2 ranges from January 2011 to December 2019. We decided to use overlapping samples to allow for a sufficiently large observation sample. The date and type of structural breaks identified by the Zivot-Andrews test are illustrated in Panel A of Fig. A1. The test is applied to the real prices of Brent oil. Panel B shows the test statistics of the conventional Augmented Dickey Fuller and the Phillips-Perron tests. The conventional unit root tests cannot account for the presence of breaks and hence fail to reject the null hypothesis of a unit root. ${ }^{17}$ In contrast, the Zivot Andrews test indicates stationarity and rejects the null hypothesis on the $1 \%$ significance level. Once we account for the presence of structural breaks, we can therefore examine the financialization in real crude oil prices rather than their percentage changes.

Panel A of Fig. A2 shows the decomposition of the total variation in real crude oil prices. The fraction of the total variation that can be attributed by structural breaks is indicated by yellow shaded areas. The share of the total variation that can be explained by movements in economic variables is indicated by green shaded areas. The percentage that can be explained by financial variables is indicated by the red shaded areas. The remaining variation is unexplained.

Overall, our set of regressors can explain a large share of the variation in real oil prices. Compared to our findings concerning returns and volatility, prices seem to be easier to predict. This could also explain why some papers prefer an analysis of oil price levels rather than percentage changes (e.g. Frankel, 2014). One drawback of analyzing price levels is that the economic determinants behind the structural breaks remain obscure. It is unclear whether they can be attributed to economic or financial factors. Compared to the analysis of returns or volatility, the inspection of price level data therefore has some disadvantages. Panel B of Fig. A2 shows the average fraction explained by each set of variables. In contrast to our findings on returns and volatility, the role of financial variables is less clear. We conclude that there is strong evidence for the increasing dominance of financial variables for explaining the variation in crude oil returns and volatility but that the analysis based on price level data is inconclusive.

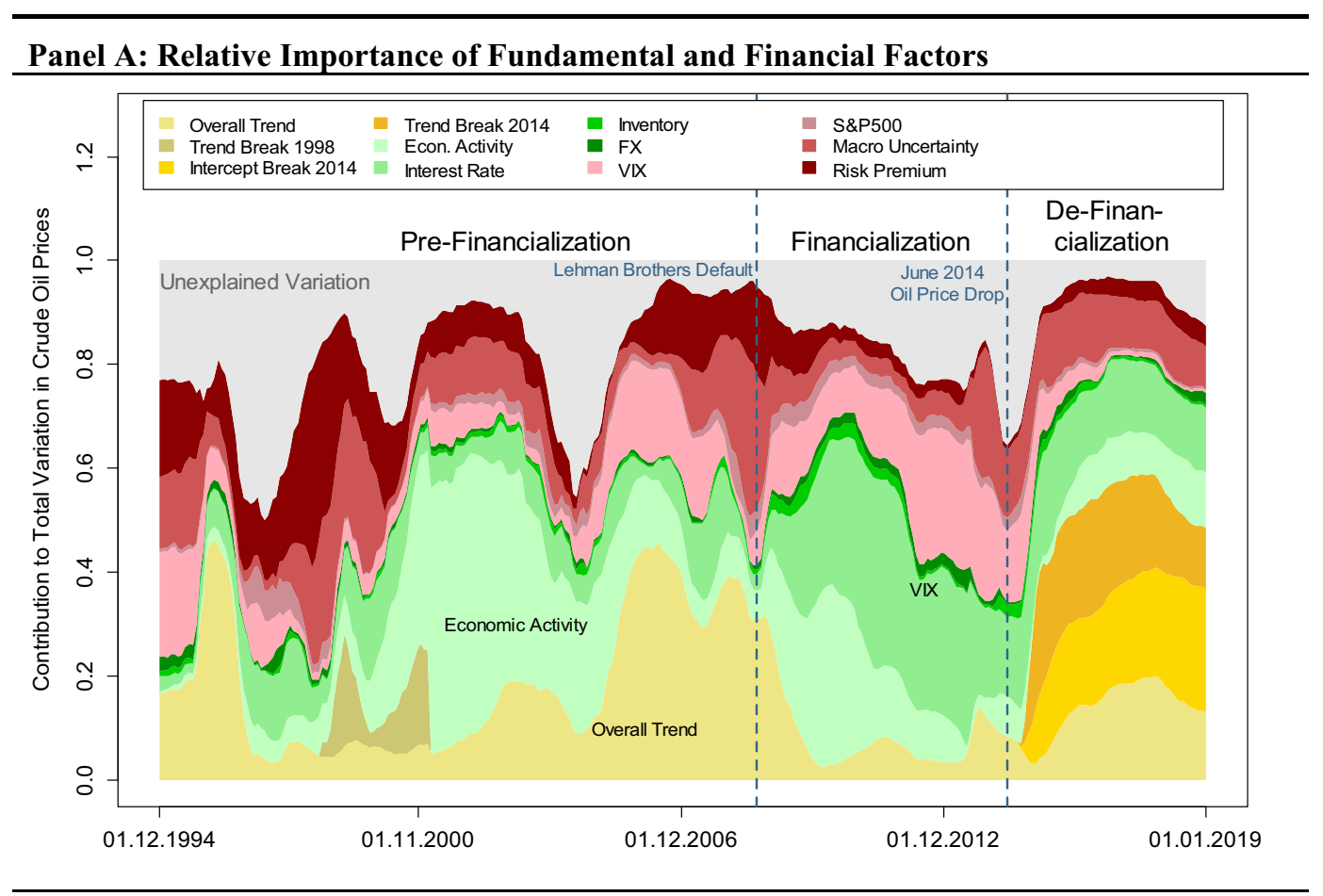

Panel B: Relative Importance Shares in Subsamples

Pre-Financialization

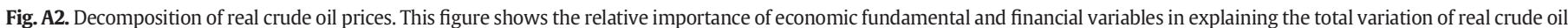

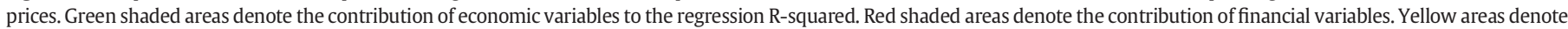

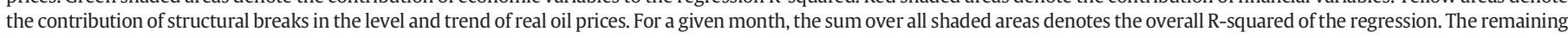
area represents the unexplained variation in real crude oil prices.

\footnotetext{
17 For the first sample, the Phillips-Perron test finds weak evidence for stationarity at the $10 \%$ level.
} 


\section{Appendix B. Summary of financialization literature}

The following table provides an overview of the financialization literature with an emphasis on papers that have been recently published in Energy Economics. The table cannot account for all papers that have been published across journals on this topic. The purpose is to give an overview of a well-cited body of established empirical research that helps to substantiate the claims made in this paper.

Table B1

Summary of financialization literature.

Adams, Z., and T. Glück (2015), Journal of Banking and Finance

The authors argue that the 2007-2009 financial crisis may have initiated and amplified the occurrence of risk spillovers to commodities, but that a style effect has replaced this crisis effect over time. The investment behavior of commodity index traders who tend to sell stocks and commodities simultaneously or in quick succession as a reaction to changes in their portfolio values characterize this style effect.

Aboura, S., Q. Nga Nguyen, J. Chevallier, Z. Lyuyuan, and B. Zhu (2020), European Journal of Operational Research

Their findings confirm the existence of financialization in commodity markets particularly after the September 2008 break. The authors show how financialization has weakened the diversification effect of commodities in a mixed-asset portfolio.

Balcilar, M., S. Hammoudeh, and E.A. Toparli (2018), Energy Economics The authors examine the volatility transmission mechanism across oil, financial markets, and CDS sectors. They evaluate the risk transmission due to several recent crisis shocks. The results indicate a complex transmission mechanism that spreads over longer periods of time. Among these events, the Lehman Brothers bankruptcy has particularly destabilizing effects on all oil-related sectors.

Basak, S., and A. Pavlova (2016) The Journal of Finance

The authors analyze how institutional investors entering commodity futures markets affect commodity prices. Institutional investors evaluate their performance relative to a commodity index. They find that all commodity futures prices, volatilities, and correlations go up with financialization, but more so for index futures than for non-index futures. They demonstrate how financial markets transmit shocks not only to futures prices but also to commodity spot prices and inventories.

Batten, J.A., H. Kinateder, P.G. Szilagyi, and N.F. Wagner (2019), Energy Economics

The authors investigate the integration between major Asian stock markets and a diversified energy portfolio that comprises oil, coal and gas. The relationship is estimated in a time-varying asset pricing framework that identifies two major regimes. The first regime represents periods of low energy-stock market integration, where markets tend to be segmented. The second regime represents periods of high integration, as characterized by limited diversification opportunities and increased levels of volatility. The two regimes differ in the way equity markets price energy risk. The authors identify a significant positive energy related equity risk premium during the high integration regime.

Baur, D.G., and T. Dimpfl (2018), Energy Economics

This paper presents an analysis of the relationship between returns and volatility of commodities. They find that the convergence of the volatility asymmetry in commodity markets towards that of equity markets is consistent with the financialization of commodity markets and the increasing role of financial factors relative to real demand and supply variables. With an equity-like asymmetric volatility effect of commodities, the volatility of equities and commodities react similarly to common shocks.

\section{Ding, H., H-G. Kim, and S.Y. Park (2016), Energy Economics}

The authors examine the interrelationship between Asian stock markets and crude oil markets. The authors confirm that Granger type causality between both markets occurs only in the tails of the return distribution. Thus, the size of spillovers depends on the underlying market conditions.

Kyrtsou, C., C. Mikropoulou, and A. Papana (2016), Energy Economics The authors employ two unorthodox nonlinear statistical methods to investigate the interdependency between the S\&P 500 stock market index and the oil market. The authors show that movements in the stock market can predict market participants' expectations for crude oil. The authors confirm that the strength of this interrelationship increases during periods of economic distress. The documented contribution of the stock market fluctuations to the spikes in the oil market revive the ongoing debate about the necessity of regulating speculators' activity during occurrence of common shocks.

Wei, Y., J. Liu, X. Lai, and Y. Hu (2017), Energy Economics

Crude oil market volatility has an important influence on policymakers' decisions and investors' financial strategies, whereas many macro-level determinants in turn are found to have important effects on oil volatility. The authors investigate economic policy uncertainty indices, especially the newly released GEPU indices, and traditional indicators in forecasting oil volatility. They investigate which determinant helps to make the most accurate daily volatility forecasts across three different forecasting horizons. Their findings show that EPU indices are comprehensive determinants, which may reflect the effects of oil demand, supply, and speculation on crude oil volatility.

Wang, X., and C. Wu (2018), Energy Economics

The authors examine the asymmetries in volatility spillovers between oil and international stock markets. They show that negative volatility spillovers are more prominent and conclude that uninformed traders and a pessimistic view are dominant in financial markets after 2009. They show that the degree of asymmetry in volatility spillovers is driven by economic and political events.

\section{References}

Aalbers, M.B., 2016. The Financialization of Housing: A Political Economy Approach. Routledge, Abingdon.

Aboura, S., Chevallier, J., Lyuyuan, Z., Nguyen, Q.N., Zhu, B., 2020. Local Gaussian correlations in financial and commodity markets. Eur. J. Oper. Res. 285, 306-323.

Adams, Z., Glück, T., 2015. Financialization in commodity markets: a passing trend or the new normal? J. Bank. Financ. 60, 93-111.

Aloui, C., Jammazi, R., 2009. The effects of crude oil shocks on stock market shifts behaviour: a regime switching approach. Energy Econ. 31 (5), 789-799.

Alquist, R., Kilian, L., 2010. What do we learn from the price of crude oil futures? J. Appl. Econ. 25 (4), 539-573.

Amano, R.A., van Norden, S., 1998. Oil prices and the rise and fall of the US real exchange rate. J. Int. Money Financ. 17, 299-316.

Aromi, D., Clements, A., 2019. Spillovers between the oil sector and the S\&P500: the impact of information flow about crude oil. Energy Econ. 81, 187-196.

Badshah, I., Demirer, R., Suleman, M.T., 2019. The effect of policy uncertainty on stockcommodity correlations and its implications on optimal hedging. Energy Econ. 84.

Bahrn, R., and B. Nikolovann (2010), "Global oil prices, oil industry and equity returns: Russian experience", Scottish Journal of Political Economy, 57(2) (2010), pp. 169-186.

Balcilar, M., Hammoudeh, S., Toparli, E.A., 2018. On the risk spillover across the oil market, stock market, and the oil related CDS sectors: a volatility impulse response approach. Energy Econ. 74, 813-827.

Barsky, R.B., Kilian, L., 2004. Oil and the macroeconomy since the 1970s. J. Econ. Perspect. 18 (4), 115-134.

Basak, S., Pavlova, A., 2016. A model of financialization of commodities. J. Financ. 71 (4), 1511-1556.

Batten, J.A., Kinateder, H., Szilagyi, P.G., Wagner, N.F., 2019. Time-varying energy and stock market integration in Asia. Energy Econ. 80, 777-792.

Baumeister, C., Kilian, L., 2016. A general approach to recovering market expectations from futures prices with an application to crude oil. CESifo Working Paper Series no. 5782 .

Baur, D.G., Dimpfl, T., 2018. The asymmetric return-volatility relationship of commodity prices. Energy Econ. 76, 378-387.

Bekaert, G., Hoerova, M., Duca, M.L., 2013. Risk, uncertainty and monetary policy. J. Monet. Econ. 60 (7), 771-788.

Bianchi, R.J., Fan, J.H., Todorova, N., 2020. Financialization and de-financialization of commodity futures: a quantile regression approach. Int. Rev. Financ. Anal. 68 (1-15).

Bicchetti, D., Maystre, N., 2012. "The Synchronized and Long-Lasting Structural Change on Commodity Markets: Evidence from High Frequency Data", UNCTAD Discussion Papers 208. available at. https://ideas.repec.org/p/unc/dispap/208.html.

Brown, G., Sarkozy, N., 2009. Oil prices need government supervision. The Wall Street J. July 8, available at. http://online.wsj.com/article/SB124701217125708963.html.

Brunnermeier, M.K., Pedersen, L.H., 2009. Market liquidity and funding liquidity. Rev. Financ. Stud. 22 (6), 2201-2238

Casella, G., Berger, R., 2002. Statistical Inference. 2nd ed. Cengage Learning.

Cheng, I.-H., Xiong, W., 2014. Financialization of commodity markets. Annual Review of Financial Economics 6, 419-441

Cheng, I.-H., Kirilenko, A., Xiong, W., 2015. Convective risk flows in commodity futures markets. Review of Finance 19, 1733-1781.

D’Amico, S., Orphanides, A., 2008. Uncertainty and Disagreement in Economic Forecasting. Federal Reserve Board Finance and Economics Discussion Series 2008-56.

Ding, H., Kim, H.-G., Park, S.Y., 2016. Crude oil and stock markets: causal relationships in tails? Energy Econ. 59, 58-69.

Dvir, E., Rogoff, K., 2009. Three Epochs of Oil. National Bureau of Economic Research Working Paper Series.

Fasianos, A., Guevara, D., Pierros, C., 2018. Have we been here before? Phases of financialization within the twentieth century in the US. Rev. Keynes. Econ. 6 (1), 34-61.

Frankel, J.A., 2014. Effects of speculation and interest rates in a "carry trade" model of commodity prices. J. Int. Money Financ. 42, 88-112.

Gibbon, P., 2013. Commodity Derivatives: Financialization and Regulatory Reform. DIIS Working Paper 2013:12, available at. https://www.diis.dk/files/media/publications/ import/extra/.

Gorton, G., Rouwenhorst, K.G., 2006. Facts and fantasies about commodity futures. NBER Working Paper No. 10595 available at. http://www.nber.org/papers/w10595.

Greene, W., 2011. Econometric Analysis. 7 e. Pearson Education.

Grömping, U., 2006. Relative importance for linear regression in R: the package relaimpo. J. Stat. Softw. 17 (1), 1-27. 
Grömping, U., 2015. Variable importance in regression models. WIREs Computational Statistics 7, 137-152.

Haase, M., Seiler Zimmermann, Y., Zimmermann, H., 2016. The impact of speculation on commodity futures markets - a review of the findings of 100 empirical studies. J. Commod. Mark. 3 (1), 1-15.

Hamilton, J.D., 1983. Oil and the macroeconomy since world war II. J. Polit. Econ. 91 (2), 228-248.

Hamilton, D.J., 2009a. Understanding crude oil prices. Energy Journal 30 (2), 179-206.

Hamilton, D.J., 2009b. Causes and consequences of the oil shock of 2007-08. Brookings Papers on Economic Activity, pp. 215-261.

Hamilton, J.D., Wu, J.C., 2014. Risk Premia in crude oil futures prices. J. Int. Money Financ. 42, 9-37.

Hartelius, K., Kashiwase, K., Kodres, L.E., 2008. Emerging market spread compression: Is it real or is it liquidity? International Monetary Fund Working Paper No. 08/10 available at. https://www.imf.org/external/pubs/ft/wp/2008/wp0810.pdf

Henderson, B., Pearson, N., Wang, L., 2015. New evidence on the financialization of commodity markets. Rev. Financ. Stud. 28 (5), 1285-1311.

Huettner, F., Sunder, M., 2012. Axiomatic arguments for decomposing goodness of fit according to Shapley and Owen values. Electronic Journal of Statistics 6, 1239-1250.

IMF (2004), “Global Financial Stability Report, Market Developments and Issues”, International Monetary Fund, available at https://www.imf.org/external/pubs/ft/gfsr/.

Irwin, S.H., Sanders, D.R., 2011. Index funds, financialization, and commodity futures markets. Applied Economic Perspectives and Policy 33 (1), 1-31.

Jurado, K., Ludvigson, S.C., Ng, S., 2015. Measuring uncertainty. Am. Econ. Rev. 105 (3), $1177-1216$.

Kaufmann, R.K., 2011. The role of market fundamentals and speculation in recent price changes for crude oil. Energy Policy 39 (1), 105-115.

Kaufmann, R.K., Ullman, B., 2009. Oil prices, speculation, and fundamentals: interpreting causal relations among spot and future prices. Energy Econ. 31 (4), 550-558.

Kilian, L., 2009. Not all oil price shocks are alike: disentangling demand and supply shocks in the crude oil market. Am. Econ. Rev. 99 (3), 1053-1069.

Kilian, L., Murphy, D.P., 2014. The role of inventories and speculative trading in the global market for crude oil. J. Appl. Econ. 29 (3), 454-478.

Kruskal, W., 1987. Relative importance by averaging over orderings. Am. Stat. 41, 6-10.

Kyrtsou, C., Mikropoulou, C., Papana, A., 2016. Does the S\&P500 index lead the crude oil dynamics? A complexity-based approach. Energy Econ. 56, 239-246.

Lee, Y.-H., Chiou, S., 2011. Oil sensitivity and its asymmetric impact on the stock market. Energy 36, 168-174.

Lindeman, R.H., Merenda, P.F., Gold, R.Z., 1980. Introduction to Bivariate and Multivariate Analysis. Scott, Foresman, Glenview, IL.
Mankiw, N.G., Reis, R., Wolfers, J., 2004. Disagreement about inflation expectations. In: Gertler, Mark, Rogoff, Kenneth (Eds.), NBER Macroeconomics Annual 2003. MIT Press, Cambridge, MA, pp. 209-248.

Nguyen, D.K., Walther, T., 2018. Modeling and forecasting commodity market volatility with long-term economic and financial variables. University of St.Gallen Working Paper No. 2018/24 available at. https://www.alexandria.unisg.ch/255910/.

Pástor, L., Veronesi, P., 2013. Political uncertainty and risk Premia. J. Financ. Econ. 110 (3), 520-545.

Perron, P., 1989. The great crash, the oil price shock, and the unit root hypothesis. Econometrica 57 (6), 1361-1401.

Qadan, M., Nama, H., 2018. Investor sentiment and the price of oil. Energy Econ. 69 42-58.

Sadorsky, P., 2000. Oil price shocks and stock market activity. Energy Econ. 21, 449-469

Sari, R., Soytas, U., Hacihasanoglu, E., 2011. Do global risk perceptions influence world oi prices? Energy Econ. 33 (3), 515-524.

Silvennoinen, A., Thorp, S., 2013. Financialization, crisis and commodity correlation dynamics. J. Int. Financ. Mark. Inst. Money 24, 42-65.

Tang, K., Xiong, W., 2012. Index investment and the financialization of commodities. Financ. Anal. J. 68 (6), 54-74.

Tori, D., Onaran, Ö., 2017. The effects of financialisation and financial development on in vestment: Evidence from firm-level data in Europe. Greenwich Papers in Political Economy no.44.

Valiante, D., Egenhofer, C., 2013. Price Formation in Commodity Markets: Financialisation and beyond. Center for European Policy Studies.

Vansteenkiste, I., 2011. What Is Driving Oil Futures Prices? Fundamentals Versus Speculations. European Central Bank Working Paper No. 1371 available at. http://ssrn.com/ abstract_id=1910590.

Wei, Y., Liu, J., Lai, X., Hu, Y., 2017. Which determinant is the most informative in forecasting crude oil market volatility: fundamental, speculation, or uncertainty? Energy Econ. 68, 141-150.

Whittaker, H., 2017. Premature financialization: a conceptual exploration. INCAS Discussion Paper no.7.

Wu, C., Wang, X., 2018. Asymmetric volatility spillovers between crude oil and international financial markets. Energy Econ. 74, 592-604.

Zhang, Y.-J., Fan, Y., Tsai, H.-T., Wei, Y.-M., 2008. Spillover effect of US Dollar exchange rate on oil prices. Journal of Policy Modelling 30 (6), 973-991.

Zhang, Y.-J., Chevallier, J., Guesmi, K., 2017. De-financialization of commodities? Evidence from stock, crude oil and natural gas markets. Energy Econ. 68, 228-239.

Zivot, E., Andrews, D., 1992. Further evidence on the great crash, the oil-price shock, and the unit-root hypothesis. J. Bus. Econ. Stat. 10 (3), 251-270. 